\title{
Randomised trials of human albumin for adults with sepsis: systematic review and meta-analysis with trial sequential analysis of all-cause mortality
}

\author{
(C) $(1)(9)$ OPEN ACCESS
}

\author{
Amit Patel specialist registrar and clinical lecturer ${ }^{123}$, Michael A Laffan professor and consultant ${ }^{3}$, \\ Umeer Waheed consultant ${ }^{1}$, Stephen $\mathrm{J}$ Brett reader and consultant ${ }^{1}$
}

${ }^{1}$ Centre for Perioperative Medicine and Critical Care Research, Imperial College Healthcare NHS Trust, Hammersmith Hospital, London W12 0HS, UK; ${ }^{2} \mathrm{MRC}$ Clinical Sciences Centre, Hammersmith Hospital, Imperial College London, London, UK; ${ }^{3}$ Centre for Haematology, Hammersmith Hospital, Imperial College London, London, UK

\begin{abstract}
Objective To assess the efficacy and safety of pooled human albumin solutions as part of fluid volume expansion and resuscitation (with or without improvement of baseline hypoalbuminaemia) in critically unwell adults with sepsis of any severity.

Design Systematic review and meta-analysis of randomised clinical trials, with trial sequential analysis, subgroup, and meta-regression analyses.

Data sources PubMed, PubMed Central, Web of Science (includes Medline, Conference Proceedings Citation Index, Data Citation Index, Chinese Science Citation Database, CAB abstracts, Derwent Innovations Index), OvidSP (includes Embase, Ovid Medline, HMIC, PsycINFO, Maternity and Infant Care, Transport Database), Cochrane Library, clinicaltrials.gov, controlled-trials.com, online material, relevant conference proceedings, hand searching of reference lists, and contact with authors as necessary.

Eligibility criteria Prospective randomised clinical trials of adults with sepsis of any severity (with or without baseline hypoalbuminaemia) in critical or intensive care who received pooled human albumin solutions as part of fluid volume expansion and resuscitation (with or without improvement of hypoalbuminaemia) compared with those who received control fluids (crystalloid or colloid), were included if all-cause mortality outcome data were available. No restriction of language, date, publication status, or primary study endpoint was applied.

Data extraction Two reviewers independently assessed articles for inclusion, extracted data to assess risk of bias, trial methods, patients, interventions, comparisons, and outcome. The relative risk of all-cause mortality was calculated using a random effects model accounting for clinical heterogeneity.
\end{abstract}

Primary outcome measure All-cause mortality at final follow-up.
Results Eighteen articles reporting on 16 primary clinical trials that included 4190 adults in critical or intensive care with sepsis, severe sepsis, or septic shock. A median of $70.0 \mathrm{~g}$ daily of pooled human albumin was received over a median of 3 days by adults with a median age of 60.8 years as part of fluid volume expansion and resuscitation, with or without correction of hypoalbuminaemia. The relative risk of death was similar between albumin groups (that received a median of $175 \mathrm{~g}$ in total) and control fluid groups (relative risk $0.94 ; 95 \%$ confidence interval 0.87 to $\left.1.01 ; P=0.11 ; l^{2}=0 \%\right)$. Trial sequential analysis corrected the $95 \%$ confidence interval for random error ( 0.85 to $1.02 ; D^{2}=0 \%$ ). Eighty eight per cent of the required information size (meta-analysis sample size) of 4894 patients was achieved, and the cumulative effect size measure ( $z$ score) entered the futility area, supporting the notion of no relative benefit of albumin (GRADE quality of evidence was moderate). Evidence of no difference was also found when albumin was compared with crystalloid fluid (relative risk $0.93 ; 0.86$ to $1.01 ; P=0.07 ; I^{2}=0 \%$ ) in 3878 patents (GRADE quality of evidence was high; $79.9 \%$ of required information size) or colloid fluids in 299 patients (relative risk 1.04; 0.79 to $1.38 ; P=0.76 ; I^{2}=0 \%$ ) (GRADE quality of evidence was very low; $5.8 \%$ of required information size). When studies at high risk of bias were excluded in a predefined subgroup analysis, the finding of no mortality benefit remained, and the cumulative $\mathrm{z}$ score was just outside the boundary of futility. Overall, the meta-analysis was robust to sensitivity, subgroup, meta-regression, and trial sequential analyses.

Conclusions In this analysis, human albumin solutions as part of fluid volume expansion and resuscitation for critically unwell adults with sepsis of any severity (with or without baseline hypoalbuminaemia) were not robustly effective at reducing all-cause mortality. Albumin seems to be safe in this setting, as a signal towards harm was not detected, but this analysis does not support a recommendation for use. 


\section{Introduction}

The use of colloid fluids is controversial and neither the efficacy nor safety of pooled human albumin solutions has been adequately demonstrated in randomised trials or meta-analyses. ${ }^{1-4}$ Uncertainty has resulted in continued global ${ }^{5}$ albumin use and associated expense. ${ }^{6}$ Human albumin is a natural colloid used as part of volume expansion and resuscitation and to correct hypoalbuminaemia. ${ }^{78}$ Sepsis, severe sepsis, and septic shock have a high mortality in adults of $24-39 \%$ in hospital ${ }^{9}$ or at 28 days and 33-50\% at 90 days. ${ }^{10}{ }^{11}$ Fluid volume expansion and resuscitation of these critically ill patients with albumin is recommended by both the UK National Institute for Health and Care Excellence (NICE) ${ }^{12}$ and the Surviving Sepsis Campaign (GRADE 2C), based on limited evidence that is of low quality. ${ }^{13-15}$ The SAFE study ${ }^{7}$ reported no difference in mortality between human albumin and crystalloid $(\mathrm{P}=0.09)$ in 1218 randomised adults with severe sepsis, of whom $36 \%$ had septic shock. ${ }^{8}$ However, mortality reduction was reported when a subgroup $(76 \%)$ with available data on covariates was subjected to multivariate logistic regression analysis $(\mathrm{P}=0.03)$, supported by persistent Kaplan-Meier survival curve separation observed after approximately eight days. ${ }^{8}$ Furthermore, the use of albumin to correct or improve hypoalbuminaemia is controversial. Cohort studies associate hypoalbuminaemia with increased morbidity and mortality in both heterogeneous ${ }^{16}$ and septic ${ }^{17}$ patients in critical or intensive care. COASST ${ }^{18}$ also suggested that human albumin infusion for severe sepsis was cost effective. However, randomised clinical trials report human albumin infusion improves only organ function ${ }^{19}$ and hypoalbuminaemia ${ }^{820}$ in these septic adults. ${ }^{21}$ Thus, it is unclear if mortality is dependent on baseline albumin concentration.

For $62 \%$ of cases human albumin infusion is not supported by consensus guideline recommendations. ${ }^{6}$ Implementation of albumin guidelines is limited by the lack of generalisability of meta-analysis findings, hindered by small information size and pooling of studies of clinically heterogeneous patient groups. A meta-analysis of 1977 patients with sepsis reported reduced mortality associated with human albumin solutions (odds ratio $0.82 ; 95 \%$ confidence interval 0.67 to $1.00 ; \mathrm{P}=0.05) .{ }^{22}$ However, this borderline difference ${ }^{23}$ was not robust to sensitivity or subgroup analyses: there was clear evidence of subgroup difference $(\mathrm{P}=0.01)$ between adults with sepsis, who did not benefit with albumin (odds ratio $0.87 ; 0.71$ to $1.07 ; \mathrm{P}=0.18$ ), and children with malaria, who did benefit (odds ratio 0.29; 0.12 to $0.72 ; \mathrm{P}=0.008){ }^{22}$. Comparison of human albumin with unavailable or seldom used fluids is also a limitation of meta-analyses used in guidelines. Hydroxyethyl starch solutions are currently not recommended ${ }^{12-14}$ in critically ill adults with sepsis according to the US Food and Drug Administration $(\text { FDA })^{24}$ and European Medicines Agency (EMA) ${ }^{25}$ because of their association with increased mortality and renal morbidity. ${ }^{26-31}$ A subsequent meta-analysis that excluded the trials of hydroxyethyl starch authored by J Boldt (implicated in research misconduct), ${ }^{32-34}$ reported that 1435 septic adults did not benefit from human albumin (relative risk of mortality $0.90 ; 95 \%$ confidence interval 0.79 to $1.02 ; \mathrm{P}=0.11){ }^{35}$

In contrast, 28 day and hospital mortality data from the EARSS and ALBIOS 2012 studies respectively (interim analysis "grey literature" included in a recent Bayesian network meta-analysis of septic adults and children with malaria) ranked albumin superior to crystalloid or hydroxyethyl starch solutions in indirect analyses designed to determine likely survival benefit. ${ }^{36}$ Hence, with emerging data from EARSS ${ }^{37}$ and ALBIOS $2014^{38}$ studies on 90 day outcomes for 2602 adults with severe sepsis and septic shock, our objective was to conduct a systematic review and meta-analysis to assess the safety and efficacy of human albumin with the research question: "what is the relative effect on all-cause mortality at final follow-up ${ }^{39}$ of pooled human albumin as part of fluid volume expansion and resuscitation (with or without improvement of hypoalbuminaemia) in critical or intensive care adults with sepsis ${ }^{40}$ of any severity (with or without baseline hypoalbuminaemia) compared with control (crystalloid or colloid) fluid?" We challenged the robustness of our findings by considering study risk of bias, trial sequential analysis, and assessed moderators with predefined subgroup and meta-regression analyses.

\section{Materials and methods}

We used the Cochrane Collaboration ${ }^{41}$ methodology to undertake, and the PRISMA (Preferred Reporting Items for Systematic Reviews and Meta-Analyses) ${ }^{42}$ statement methodology to report, a systematic review and meta-analysis of randomised clinical trials. The relative effect of pooled human albumin solutions as part of fluid volume expansion and resuscitation, with or without improvement of hypoalbuminaemia, of adults in critical or intensive care with sepsis of any severity, with or without baseline hypoalbuminaemia, was investigated in comparison with control crystalloid or colloid fluid. The primary outcome measure was all-cause mortality at final follow-up, ${ }^{39}$ with predefined subgroup analyses of studies at high risk of bias compared with low or unclear risk of bias. ${ }^{413}$ The study was not registered.

\section{Eligibility criteria}

All of the following criteria were met for inclusion of a study: 1. Prospective randomised clinical trial reporting on adults in a critical or intensive care unit setting that have not been retracted

2. Trial or subgroup of patients diagnosed before or at randomisation with sepsis of any severity (including sepsis, severe sepsis, and septic shock), with or without baseline hypoalbuminaemia, receiving intravenous fluid as part of volume expansion and resuscitation, with or without improvement of hypoalbuminaemia

3. At least one exposure group that received intravenous human albumin solution of any concentration or type in any carrier solution after randomisation

4. At least one control group that received any intravenous fluid (crystalloid or colloid) of any strength or type in any carrier solution after randomisation

5. Availability of all-cause mortality outcome data in the patients and comparison groups identified with criteria 1 to 4.

\section{Identification of studies}

A literature search of PubMed, PubMed Central, Web of Science (includes Medline, Conference Proceedings Citation Index, Data Citation Index, Chinese Science Citation Database, CAB abstracts, Derwent Innovations Index), OvidSP (includes Embase, Ovid Medline, HMIC, PsycINFO, Maternity and Infant Care, Transport Database), and the Cochrane Library was undertaken to identify randomised clinical trials. Further unpublished studies and grey literature ${ }^{44}$ were sought from clinicaltrials.gov, controlled-trials.com, free Google search, supplementary material published online including international manufacturer and product datasheets, and relevant conference 
proceedings for the previous four years. The searches were last updated on 17 March 2014. The search terms used were "sepsis" with "albumin" or "albumins," and "randomized" or "randomised." No language, date, publication status, or predefined outcome restriction were applied. Reference lists of evaluable studies, systematic reviews, meta-analyses, narrative reviews, and reports were also hand searched for additional studies eligible for inclusion. Reference management for published studies was with Endnote X6 (Build 8318).

\section{Selection of studies}

Two reviewers independently screened and excluded the initially identified articles from the literature search on the basis of title and abstract if they were obviously not relevant. Full text articles of potentially eligible studies were independently assessed by two reviewers against the eligibility criteria. Disagreements were resolved in meetings or referred to a third reviewer for resolution.

\section{Data extraction}

For each study, data extraction was undertaken independently by two reviewers using a pre-made extraction form. Data on the following study characteristics were collected if available: centres, countries, ${ }^{45}$ dates of patient study, number of randomised patients with sepsis of any severity, trial primary reported endpoint, and time of final mortality assessment. ${ }^{39}$ To assist comparison between studies, patients were reclassified into "sepsis," "severe sepsis," and "septic shock" clinical severity diagnostic groups. ${ }^{40}$ Sufficient data to calculate baseline (comparison group) all-cause mortality, observed power, ${ }^{46}$ relative and absolute risk reductions, were also collected.

Baseline patient characteristics of the albumin intervention group were collected on sex, age, illness severity (SOFA, ${ }^{47}$ APACHE II ${ }^{48}$ SAPS $\left.\mathrm{II}^{49}\right)$, vasopressor use and lactate level (markers of septic shock), ${ }^{39}$ albumin level, pulmonary infection focus, mechanical ventilation, acute respiratory distress syndrome, renal replacement therapy, and medical/surgical case mix. Acute respiratory distress syndrome was reclassified according to the Berlin definition ${ }^{50}$ where possible to facilitate comparison between trials.

Intervention details were extracted. The indication, intervention method, timing of intervention initiation, desired intervention targets, intervention exposure time, types of interventions (concentration of human albumin with brand and manufacturer; comparison fluid type), intervention dose (to calculate daily and total dose, total and volume), were also recorded. If more than one suitable randomised comparison group was reported, these were combined as appropriate into comparison fluid categories: control (all non-human albumin groups), crystalloid, or colloid.

Data on the predefined primary outcome of all-cause mortality were collected in relation to the patients enrolled at baseline. ${ }^{41}$ When mortality was reported at different follow-up intervals, data from the longest complete follow-up was used. ${ }^{39}$ For published studies, we contacted the corresponding author for clarification of specific sepsis mortality data for individual intervention group if required, if this had not been attempted by a previous systematic review. We also contacted the lead investigators of unpublished registered trials that had not presented data of their final mortality outcome. Data on early ( $\leq 24$ hour) and post-intervention albumin levels in the pooled human albumin groups were collected, and their difference from pre-intervention baseline calculated. If these data were not reported in the text of articles, we estimated values from their figures if available.

\section{Assessment of risk of bias}

Two reviewers independently assessed the risk of bias of individual studies, and with bias domains across studies, using the Cochrane collaboration tool. ${ }^{41}{ }^{43}$ RevMan version 5.2.9 (Java 6 ) was used to construct summaries. The domains of assessment for the outcome of all-cause mortality were selection (sequence generation and allocation concealment), performance, detection, attrition, selective reporting, research misconduct or duplicate publication, and other bias. Blinding (for performance bias assessment) of intervention fluid was considered to confer low risk of bias if healthcare staff and patients were blind to group allocation and efforts had been made to conceal fluids and administration equipment. The risk of performance bias was considered unclear if a fixed albumin dose schedule was used without blinding, or if blinding was reported but to a lesser degree than required for low risk of bias. Otherwise, if a variable albumin dose schedule was reported, the risk of bias was considered high without adequate blinding. The other bias category included a bias of any potential source. ${ }^{41} \mathrm{~A}$ trial was considered as high risk of bias overall if one or more individual bias assessment domains were judged to be at high risk. If all individual bias domains were judged to be low risk, a study was considered low risk of bias overall. If one or more individual bias assessment domains was judged to be of unclear risk of bias, the overall trial risk of bias was considered low (if reviewers judged that key domains were at low risk and the unclear risk domains were unlikely to seriously alter the results) or unclear (if key domains were judged to be at unclear risk of bias, raising some doubt about the results) ${ }^{41}{ }^{43}$ Publication bias was assessed by visual judgement of a funnel plot and by Egger's regression. ${ }^{51}{ }^{52}$

\section{Grading the quality of evidence}

The quality of evidence was assessed with GRADE (Grading of Recommendations, Assessment, Development and Evaluation) methodology by a panel of four reviewers with experience of critical/intensive care medicine, haematology, anaesthesia, and general (internal) medicine. ${ }^{15}$ Quality of evidence was classified as high, moderate, low, or very low based on the judgements for the outcome of all-cause mortality regarding risk of bias, inconsistency, indirectness, imprecision, and other considerations (publication bias). ${ }^{15}{ }^{53}$ GRADE was applied to each human albumin fluid comparison, then to each predefined risk of bias subgroup. Summary tables were constructed with GRADEpro version 3.6.

\section{Statistical analysis}

The primary outcome summary effect measure was relative risk of all-cause mortality ${ }^{39}$ of pooled human albumin solutions compared to control, crystalloid, or colloid fluid. Predefined subgroup analysis was by risk of bias (high compared with low or unclear risk of bias). ${ }^{41}$ Other predefined subgroup and meta-regression $^{54}$ analyses were undertaken to investigate statistical, methodological, and clinical heterogeneity that may relate to effect size for each albumin comparison. Subgroups of individual bias domains were assessed (selection, performance, detection, attrition, reporting, research misconduct or duplicate publication, and other bias) ${ }^{41}{ }^{43}$ Further predefined bias type subgroups were author bias (J Boldt or others), ${ }^{22} 3132$ time bias (before or after Surviving Sepsis Campaign), ${ }^{13} 141$ data source bias (journal articles or conference proceedings), ${ }^{31}$ small study bias (multicentre or single centre; $<100$ patients per group), ${ }^{31556}$ and location bias (continent). ${ }^{314}$ Predefined clinical subgroups were disease severity (sepsis, severe sepsis, severe 
sepsis and septic shock, or septic shock), ${ }^{40} 5758$ time of all-cause mortality observation ( $\geq 90$ days, $\geq 28$ to $<90$ days, hospital, or intensive care unit mortality), ${ }^{26} 39$ intervention method (fixed or variable albumin dosing protocol) ${ }^{2260}$ and type (hypooncotic (4-5\%) or hyperoncotic (20\%) human albumin concentration), ${ }^{22}{ }^{60}$ intervention timing (early infusion), ${ }^{37} 3861$ and comparison colloid type (gelatin; $6 \%$ tetrastarch $130 \mathrm{kDa}$ or other hydroxyethyl starches). ${ }^{26} 2931596263$ Predefined continuous clinical covariates were baseline sepsis or disease severity (vasopressor use and lactate as indicators of septic shock), ${ }^{39} 40575864$ baseline (comparison group) mortality, intervention duration (days of infusion), intervention exposure/dose/volume (daily and total human albumin), baseline albumin level, early ( $\leq 24$ hours) and post-intervention albumin level (and respective changes from baseline). ${ }^{19} 546566$ Baseline markers of sepsis related clinical covariates (pulmonary site of infection, invasive ventilation, acute respiratory distress syndrome, renal replacement therapy) were also regressed. ${ }^{39}$ As $>6-10$ data points are generally required to draw meaningful conclusions from meta-regression, we did not present the analysis by risk of bias if the number of studies after exclusion of those at high risk of bias was below this threshold. ${ }^{54}$

The relative risk of death for human albumin compared to control or crystalloid or colloid fluids was calculated for each included study. A pooled summary relative risk of these studies and their $95 \%$ confidence intervals was then calculated for each fluid comparison. $\mathrm{P}$ values of $\leq 0.05$ and relative risk point estimate $95 \%$ confidence intervals that excluded the null $(<1.00$ or $>1.00$ ) were considered statistically significant. Continuity correction was not required as no zero event trials were identified. Statistical heterogeneity was assessed using the $\chi^{2}$ test (Cochran Q) and $\mathrm{I}^{2}$ statistic. ${ }^{67}{ }^{68}$ Heterogeneity was suggested if $\mathrm{Q}>\mathrm{df}$ (degrees of freedom) and present if $\mathrm{P} \leq 0.10$. $\mathrm{I}^{2}$ values of $0-24.9 \%, 25-49.9 \%, 50-74.9 \%$, and $75-100 \%$ were considered as none, low, moderate, and high thresholds for statistical heterogeneity. ${ }^{67}{ }^{6} \mathrm{~A}$ random effects model ${ }^{69}$ (Mantel-Haenszel method) was used in the presence of statistical heterogeneity or a judgment of potential clinical heterogeneity. $\tau^{2}>1$ suggested heterogeneity. ${ }^{41}$ Mixed effects univariate meta-regression (unrestricted maximum likelihood) was used to allow for residual heterogeneity and to explore the observational effect of continuous covariates on effect size..$^{415254}$

Sensitivity analysis was performed by using a fixed effects model (Mantel-Haenszel method), odds ratios with both random and fixed effects models, exclusion of the largest trial, exclusion of the most weighted trial, and exclusion of the trial with highest observed power. Analysis by excluding studies at high risk of bias was part of a predefined subgroup analysis. ${ }^{41}$ Sensitivity analysis with trial sequential analysis was performed to correct for random error and repetitive testing of accumulating and sparse data; meta-analysis monitoring boundaries and required information size (meta-analysis sample size) were quantified, along with $\mathrm{D}^{2}$ (diversity adjusted information size) and adjusted $95 \%$ confidence intervals. ${ }^{70-73}$ Risk of type 1 error was maintained at $5 \%$ with a power of $80 \%$. Baseline (comparison group) mortality was based on that of the included trials not at high risk of bias, ${ }^{59}$ and a clinically meaningful anticipated relative mortality reduction of $10 \%$ was used based on the lowest and most conservative value from power calculations presented for included recent sepsis trials investigating a primary mortality endpoint. ${ }^{37}{ }^{38}$ Trial sequential analysis $95 \%$ confidence interval boundaries that excluded the null $(<1.00$ or $>1.00)$ were considered statistically significant. The same trial sequential analysis specifications were used to model the potential effect of uncompleted registered studies. Exploratory analysis with other large trials that did not meet the inclusion criteria was also undertaken if clinical interest was considered likely.

RevMan version 5.2.9 (Java 6) was used for meta-analysis and funnel plots. TSA viewer version $0.9 \beta$ was used for trial sequential analysis. Comprehensive Meta-analysis version 2.2.064 was used for Egger's regression and meta-regression. OpenEpi version 2.3 was used for observed power (at 95\% confidence interval without continuity correction as no zero event studies were identified). Online calculators (graphpad.com and clinicalevidence.bmj.com) were used for relative and absolute risk reductions and increases, and number need to treat or harm. Microsoft Excel version 14.2.4 was used for data management and simple calculations, including means, medians, and standard deviations.

\section{Results}

The literature search is summarised in figure $1 \Downarrow$. Eighteen articles $^{7837} 38$ 74-87 reporting 16 randomised clinical trials studied 4190 adults with sepsis, severe sepsis, and septic shock, randomised to receive pooled human albumin or comparison fluid as part of volume expansion and resuscitation (with or without improvement of baseline hypoalbuminaemia) in an intensive or critical care setting between 1982 and 2012.

All trials were published in English and two were companion articles. $^{85}$ The 90 day mortality outcome results of EARRS ${ }^{37}$ were presented orally at the 24th Annual Congress of the European Society of Intensive Care Medicine; those of $\mathrm{ALBIOS}^{38}$ were communicated to us by the senior author before publication, representing a combined total 2602 patients. Sepsis subgroup or comparison fluid group mortality data for three studies ${ }^{79} 8287$ had been obtained from a previous author data request. ${ }^{22}$ Our other data requests were unsuccessful. ${ }^{87}$ Further relevant data were obtained from online sources (www.esicm. org/flash-conferences/berlin-2011) and article supplementary appendices.

Although not mutually exclusive, the exclusion of studies was because eligibility criteria were not met, ${ }^{19} 61$ 88-103 duplicate publication, ${ }^{104-106}$, or ongoing patient recruitment without availability of mortality outcome data. ${ }^{107}$ The multicentre open-label CRISTAL ${ }^{61}$ trial reported 90 day mortality outcomes in a predefined subgroup of septic adults randomised to variable doses of colloid or crystalloid fluids, and 616 patients received albumin, which was permitted by both fluid groups for hypoalbuminaemia of $<20 \mathrm{~g} / \mathrm{L}$ in a non-randomised manner, and thus was excluded. RASP ${ }^{107}$ is an ongoing registered (NCT01337934) blinded Brazilian trial that will randomise 360 patients with severe sepsis to either hypooncotic (4\%) human albumin or crystalloid (lactated Ringer solution). CRISTAL ${ }^{61}$ and $\mathrm{RASP}^{107}$ did not meet our inclusion criteria but were used in exploratory trial sequential analysis models for clinical interest and hypothesis generation (see online data supplement). Overall, this systematic review and meta-analysis comprises $62.1 \%$ new severe sepsis and septic shock patient information by inclusion of previously unpooled ALBIOS $^{38}$ and EARSS ${ }^{37}$ 90 day mortality outcome data.

\section{Randomised trial characteristics}

The study characteristics extracted from the 16 primary trials are outlined in tables $1 \Downarrow$ and $2 \Downarrow$. Three primary trials ${ }^{78} 3738$ were multicentre and designed to investigate the endpoint of all-cause mortality in 3820 randomised patients with severe sepsis and septic shock. In all, 2893 patients in critical or intensive care units were randomised across Europe, ${ }^{37} 3874-798285-871218$ across Australasia, ${ }^{78}$ and 79 across North America. ${ }^{80} 818384$ Eleven 
trials $^{7837387880-87}$ recruited 4032 patients with severe sepsis and septic shock; only three trials ${ }^{37} 8083$ recruited 827 patients exclusively with septic shock. The median study sample size was 29 patients (range 17 to 1810). Median baseline (control fluid group) mortality was $38.0 \%$ (range $13.3 \%$ to $91.7 \%$ ), and median observed study power for this outcome was only $6.0 \%$ (range $1.1 \%$ to $40.0 \%$ ).

\section{Sepsis patient characteristics}

Sepsis patient characteristics extracted from the 16 primary clinical trials are outlined in table $1 \Downarrow$ and the online data supplement. The median age of adults exposed to human albumin solutions was 60.8 years (range 45.0-76.0), with men representing 65.7\% (range 38.4-86.7\%). ${ }^{78} 373876$ 78-87 Medical patients comprised a median of $0 \%$ (range $0-78.1 \%$ ) or a mean of $28.2 \%$ (standard deviation 29.2\%). ${ }^{78373874-7882}$ A disease severity summary measure was not possible because of varied scoring systems and reporting. However, the median proportion of patients who required vasopressors or inotropes (an indication of septic shock) was 64.8\% (range 21.4-100\%) $7837387476-808385-87$ and the median serum lactate concentration was $2.2 \mathrm{mmol} / \mathrm{L}$ $(0.2-6.6 \mathrm{mmol} / \mathrm{L}){ }^{37} 38778083-87$ The median proportion of mechanically ventilated patients was $100 \%$ $(50.0-100 \%),{ }^{7837} 3874-79818284-87$ pulmonary site of infection was $44.1 \%(33.3-66.7 \%),{ }^{78} 3738788184-86$ and acute respiratory distress syndrome was $17.6 \%(0-100 \%) .^{7874.767879818586}$ The baseline median renal replacement therapy use was $3.8 \%$ (0-22.6\%) based on three studies. ${ }^{78778}$ The median baseline serum albumin concentration was $20.8 \mathrm{~g} / \mathrm{L}(11.0-25.0 \mathrm{~g} / \mathrm{L}) .^{78} 37387885-87$

\section{Fluid interventions}

In total, 2068 patients were exposed to pooled human albumin solutions as outlined in table $2 \Downarrow$ and the online supplement. Median albumin exposure was $175.0 \mathrm{~g}$ (16.0-180.0 g) for a median of 3 days (40 minutes-28 days) in a median volume of 1.7 L (0.4-3.4 L). ${ }^{78} 373874-8183-87$ Thus the median daily albumin exposure was $70.0 \mathrm{~g}(16.0-300.0 \mathrm{~g})$. Early infusion ${ }^{78}$ within $6,{ }^{37} 3812,{ }^{8586}$ and 24 hours $^{74} 7787$ was described in seven trials. Five studies ${ }^{37} 38787987$ used a fixed predefined protocol with a median of $40.0 \mathrm{~g}$ daily (range $16-60 \mathrm{~g}$ ) for 3 days ( 40 minutes-28 days), representing a total median exposure of 180.0 $\mathrm{g}(16-220 \mathrm{~g})$ in $0.9 \mathrm{~L}(0.4-1.1 \mathrm{~L})$.

Three studies were designed to improve hypoalbuminaemia in addition to fluid volume expansion and resuscitation. ${ }^{37} 38$ Early ( $\leq 24$ hours) improvement of hypoalbuminaemia resulted in a median albumin concentration of $26.5 \mathrm{~g} / \mathrm{L}(24.0-28.6 \mathrm{~g} / \mathrm{L})$, representing a median increase from baseline of $5.4 \mathrm{~g} / \mathrm{L}$ $(1.0-16.0 \mathrm{~g} / \mathrm{L}){ }^{78} 37388586$ The median overall post-intervention hypoalbuminaemia was $28.0 \mathrm{~g} / \mathrm{L}(25.0-29.5 \mathrm{~g} / \mathrm{L})$, representing a median increase from baseline of $5.7 \mathrm{~g} / \mathrm{L}(5.3-16.0 \mathrm{~g} / \mathrm{L})$ with treatment. ${ }^{783738788586}$ ALBIOS $^{38}$ and SAFE $^{78}$ intervention protocols were $\leq 28$ days or intensive care unit length of stay, but their respective medians were 9 and 8.2 days. The median post-intervention albumin concentration on day 7 was $27.2 \mathrm{~g} / \mathrm{L}$ (25.0-29.4 g/L) for $\mathrm{ALBIOS}^{38}$ and SAFE, ${ }^{78}$ with a median increase from baseline of $2.8 \mathrm{~g} / \mathrm{L}(1-4.5 \mathrm{~g} / \mathrm{L})$.

Comparison fluid exposures were crystalloids $(0.9 \%$ saline, Ringer's lactate) received in control group arms by 2122 patients, ${ }^{78373874-87}$ and colloids (hydroxyethyl starch, gelatin) by 156 patients. ${ }^{74-80}{ }^{82-87}$ Exposure to $6 \%$ tetrastarch $130 \mathrm{kDa}$ occurred in 36 patients across two small studies, ${ }^{78} 82$ and gelatin in six patients. ${ }^{85} 86$

\section{Risk of bias assessment}

Assessment of within study bias (internal validity) is summarised in figure $2 \Downarrow$. All studies were judged to be of unclear risk of bias in at least one bias assessment domain. Ten studies s4-77 80-84 $87^{87}$ had at least one high risk of bias judgment for the outcome of mortality, and were therefore considered at high risk of bias overall. The remaining six studies ${ }^{7837} 3878798586$ were considered at low risk of bias overall as reviewers judged that key domains were at low risk of bias and the domains at unclear risk of bias were unlikely to have seriously altered the results for the outcome of all-cause mortality.

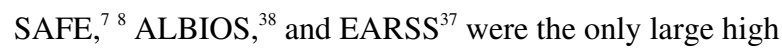
quality studies designed to assess the endpoint of mortality, and reported on 3820 patients with severe sepsis and septic shock. However, only EARSS ${ }^{37}$ and $\operatorname{ALBIOS}^{38}$ collected 90 day mortality data on 2602 patients, of whom 1927 had septic shock. ALBIOS reported baseline group imbalance for central venous oxygen saturation $(\mathrm{P}=0.02)$ and organ dysfunction $(\mathrm{P}=0.04){ }^{38}$ Full publication of EARSS is awaited. ${ }^{37} \mathrm{SAFE}^{78}$ was the only double blind study that adequately concealed fluid group allocation in 1218 patients, and would have been classified as low risk of bias for all assessment domains had baseline blood pressure been similar between groups $(\mathrm{P}=0.03)$. To prevent the unnecessary introduction of bias that would have classified SAFE 2011 as at high risk of bias, ${ }^{35} 4110810928$ day mortality outcome data from SAFE $2004^{7}$ was used rather than multivariate adjusted data from SAFE $2011,{ }^{8}$ which excluded $24.5 \%$ of enrolled patients. All the other studies described patients exposed to open-label fluid interventions, with a variable dosing schedule, except for five that used a predefined fixed dose. 3738787987

Bias domains were judged as high risk of bias because: variable dose fluid exposures were not associated with any attempts at blinding ${ }^{80-84}$ there was inconsistency between the originally reported ${ }^{87} 27$ severe sepsis patients and the author supplied group mortality data on 33 sepsis patients, ${ }^{22}$ risk of duplicate publication bias affecting 35 patients, ${ }^{80}{ }^{83}$ risk of research misconduct in studies affecting 116 patients, ${ }^{74-77}$ and pre-randomisation interventions that might enhance or diminish the effect of the randomised fluids. Overall, 10 studies s4-77 80-84 $87^{-1}$ at high risk of bias studied 248 patients, comprising $5.9 \%$ of the patient data in this systematic review and meta-analysis.

The assessment of bias risk domains across studies (external validity) shows that, although all bias domains, except detection bias, had unclear or high risk, overall most of the information for the outcome of all-cause mortality came from data at low risk of bias (online supplement).

\section{Primary clinical outcome: all-cause mortality All-cause mortality with albumin compared with control fluid}

Mortality data were available for 16 randomised clinical trials including 4190 patients with sepsis, severe sepsis, and septic shock who received either human albumin solutions or control fluids. The required information size was 4894 patients for $80 \%$ power and an $\alpha$ of 0.05 . All-cause mortality was statistically similar between these two fluid groups (relative risk 0.94; $95 \%$ confidence interval 0.87 to $1.01 ; \mathrm{P}=0.11$ ) (fig $3 \Downarrow$ ). Statistical heterogeneity was not present $\left(\mathrm{I}^{2}=0 \% ; \chi^{2} 5.61, \mathrm{df}=15, \mathrm{P}=0.99\right.$; $\tau^{2} 0.00$ ). The finding was robust to sensitivity analysis (lowest $\mathrm{P}$ value 0.06 ) (tables $3 \Downarrow$ and $4 \Downarrow$, plus online supplement), and clear evidence of publication bias was not present $(\mathrm{P}=0.29)$. Trial sequential analysis correction of the $95 \%$ confidence 
interval $\left(0.87\right.$ to $\left.1.02 ; \mathrm{D}^{2}=0 \%\right)$ did not alter the finding of no mortality benefit with human albumin (fig $4 \Downarrow$ ).

Predefined subgroup, meta-regression, and trial sequential analyses are summarised in tables $3 \Downarrow$ and $4 \Downarrow$ (see also the online supplement). The test for subgroup difference demonstrated a trend for the risk of bias domain "research misconduct or duplicate publication" bias $\left(\mathrm{I}^{2}=38.6, \chi^{2}=1.63, \mathrm{df}=1, \mathrm{P}=0.20\right)$. A borderline trend towards benefit of albumin was observed after studies at high risk of bias for this bias domain were excluded (relative risk 0.93 ; $95 \%$ confidence interval 0.86 to 1.00 ; $\mathrm{P}=0.06$ ). Baseline hypoalbuminaemia, albumin improvement, or sepsis severity (including subgroup analysis by baseline septic shock: relative risk $0.92 ; 0.83$ to $1.02 ; \mathrm{P}=0.10$ ) determined in different ways were not robustly associated with improved survival in albumin treated patients (tables $3 \Downarrow$ and $4 \Downarrow$, online supplement).

The cumulative $\mathrm{z}$ score crosses the boundary of futility, suggesting further trials are not required as they are unlikely to demonstrate reduced mortality with albumin, and even less likely to show increased mortality (fig $4 \Downarrow$ ). A model including the ongoing RASP trial ${ }^{107}$ increased the information size to $93.0 \%$, but this still did not alter the finding of no overall mortality benefit (online supplement). This was also the case for the model including patients with sepsis who received albumin in the CRISTAL trial ${ }^{61}$ (online supplement).

Overall, with $85.6 \%$ of the required information size, the number needed to treat was 37 patients (95\% confidence interval: the number needed to treat is $>18$, and the number needed to harm is $>517$ ) for the comparison of albumin with control fluid. GRADE quality of evidence was judged to be moderate (table $5 \Downarrow)$.

\section{All-cause mortality with albumin compared with control fluid by risk of bias}

Exclusion of trials at high risk of bias left six studies including 3942 patients, which moved the point estimate further towards benefit with human albumin (relative risk $0.93 ; 95 \%$ confidence interval 0.86 to $1.01 ; \mathrm{P}=0.07$ ), but this was not statistically significant (fig $3 \Downarrow$ ). The required information size was 4894 .

Statistical heterogeneity was not present $\left(\mathrm{I}^{2}=0 \% ; \chi^{2} 1.76, \mathrm{df}=5\right.$, $\left.\mathrm{P}=0.88 ; \tau^{2} 0.00\right)$. Overall, the finding was robust to sensitivity analysis, although a trend towards borderline statistical significance (lowest $\mathrm{P}$ value 0.06 ) was observed, particularly with a fixed effects model (relative risk $0.93 ; 0.85$ to 1.00 ; $\mathrm{P}=0.06$ ) (online supplement). Clear evidence of publication bias was not present $(\mathrm{P}=0.39)$. Trial sequential analysis correction of the $95 \%$ confidence interval $\left(0.85\right.$ to $\left.1.02 ; \mathrm{D}^{2}=0 \%\right)$ did not alter the notion of no benefit with albumin.

In the trial sequential analysis, the cumulative $\mathrm{z}$ score is close to the boundary of futility and further from the sequential monitoring boundary of benefit (fig $4 \Downarrow$ ), indicating that further studies are unlikely to alter the conclusion of no benefit with albumin. A model including data from RASP ${ }^{107}$ increased the information size to $87.9 \%$ when attributed a relative risk of 0.9 , resulting in the cumulative $\mathrm{z}$ score touching the conventional boundary of benefit $(\mathrm{P}=0.05)$ but not the trial sequential monitoring boundary of benefit (corrected $95 \%$ confidence interval 0.85 to $1.02 ; \mathrm{D}^{2}=0 \%$ ) (online supplement). However, an exploratory model including patients with sepsis from the CRISTAL trial ${ }^{61}$ who received only albumin was not associated with survival benefit, although this study would probably be considered high risk of bias and thus excluded from this analysis, and is mentioned here for clinical interest only (online supplement).
Overall, the tests for subgroup difference and heterogeneity were not statistically significant between studies at high risk of bias (that included 248 patients) and studies at low or unclear risk of bias (fig $3 \Downarrow$ ). However, statistical heterogeneity that was low was introduced $\left(\mathrm{I}^{2}=27.1 \%, \chi^{2}=1.37, \mathrm{df}=1, \mathrm{P}=0.24\right)$ with a fixed effects model using relative risk estimates (tables $3 \Downarrow$ and $4 \Downarrow$, online supplement). When studies at low risk of bias were examined by sepsis subgroup (sepsis, severe sepsis, septic shock), no statistically significant benefit was observed for each individual group (for septic shock, relative risk 0.91; 95\% confidence interval 0.81 to $1.01 ; \mathrm{P}=0.09$ ), but overall borderline benefit was demonstrated (relative risk $0.92 ; 0.85$ to 1.00 ; $\mathrm{P}=0.05$ ) (online supplement). However, this was not robust to trial sequential analysis correction of the $95 \%$ confidence interval ( 0.84 to $1.01 ; \mathrm{D}^{2}=0 \%$ ) (online supplement), and sensitivity analysis as the null could not be excluded: fixed effects model (relative risk $0.93 ; 0.85$ to $1.00 ; \mathrm{P}=0.06$ ); odds ratios with a random effects model (odds ratio $0.89 ; 0.77$ to $1.00 ; \mathrm{P}=0.08$ ) or fixed effects model (odds ratio $0.88 ; 0.78$ to $1.01 ; \mathrm{P}=0.06$ ). Furthermore, the finding was not robust to exclusion of either SAFE ${ }^{7}$ or ALBIOS. ${ }^{38}$ No benefit with albumin was also observed when severe sepsis and septic shock were grouped together (tables $3 \Downarrow$ and $4 \Downarrow$, online supplement). Overall, with $80.5 \%$ of the required information size, the number needed to treat was 37 patients $(95 \%$ confidence interval: number needed to treat is $>18$ and the number needed to harm is $>297$ ) for the comparison of albumin with control fluid excluding trials at high risk of bias. The overall GRADE quality of evidence was judged to be high (table $5 \Downarrow$ ).

\section{All-cause mortality with albumin compared with crystalloid fluids}

Seven clinical trials randomised 3878 patients and compared human albumin with crystalloid fluids. The required information size was 4856 patients for $80 \%$ power and an $\alpha$ of 0.05 . Mortality was similar for both fluid groups (relative risk 0.93 ; $95 \%$ confidence interval 0.86 to $1.01 ; \mathrm{P}=0.07$ ) (fig $5 \Downarrow$ ).

Statistical heterogeneity was not present $\left(\mathrm{I}^{2}=0 \% ; \chi^{2}=1.12, \mathrm{df}=6\right.$, $\left.\mathrm{P}=0.98 ; \tau^{2}=0.00\right)$. The finding was robust to sensitivity analyses (tables $3 \Downarrow$ and $4 \Downarrow$, online supplement). Clear evidence of publication bias was not detected $(\mathrm{P}=0.91)$. Trial sequential analysis correction of the $95 \%$ confidence interval ( 0.85 to 1.02 ; $\mathrm{D}^{2}=0 \%$ ) did not alter the finding of no mortality benefit with human albumin (fig 6џ).

Predefined subgroup and meta-regression analyses are summarised in tables $3 \Downarrow$ and $4 \Downarrow$ (plus online supplement); these did not alter the finding of no benefit with albumin, except when sepsis severity subgroups were used by separating ALBIOS ${ }^{38}$ severe sepsis and septic shock patient data (these were post hoc unadjusted outcomes). There was statistically significant overall benefit observed with albumin (relative risk $0.93 ; 95 \%$

confidence interval 0.86 to $1.00 ; \mathrm{P}=0.05$ ), but no single sepsis severity subgroup benefited. The strongest borderline trend was observed in the septic shock subgroup (relative risk $0.91 ; 0.82$ to $1.01 ; \mathrm{P}=0.06$ ). However, the overall signal of benefit was not robust to sensitivity analyses: fixed effects model (relative risk $0.93 ; 0.86$ to $\left.1.01 ; \mathrm{P}=0.07 ; \mathrm{I}^{2}=0 \%\right)$; odds ratios with random or fixed effects models (odds ratio $0.89 ; 0.78$ to $1.01 ; \mathrm{P}=0.07$; $\mathrm{I}^{2}=0 \%$ ); exclusion of $\mathrm{SAFE}^{78}$ (relative risk $0.94 ; 0.86$ to 1.03 ; $\mathrm{P}=0.19 ; \mathrm{I}^{2}=51.3 \%$ ) or $\mathrm{ALBIOS}^{38}$ (relative risk $0.92 ; 0.82$ to 1.02 ; $\left.\mathrm{P}=0.13 ; \mathrm{I}^{2}=0 \%\right)$. Trial sequential analysis correction of the $95 \%$ confidence interval ( 0.85 to $\left.1.01 ; \mathrm{D}^{2}=0 \%\right)$, and the observation that the cumulative $\mathrm{z}$ score did not reach the trial sequential monitoring boundary of benefit (online supplement) support the view that albumin was not beneficial or harmful. 
Furthermore, survival benefit was not observed when other markers of septic shock were used for meta-regression analysis (table $4 \Downarrow$ ), and the septic shock subgroup itself was not robust to sensitivity or trial sequential analyses (online supplement).

The cumulative $\mathrm{z}$ score is between the conventional $\alpha$ boundary of 0.05 and the futility boundary, but further from the corrected significance trial sequential monitoring boundary for benefit

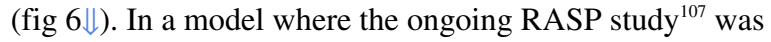
assigned a relative risk of 0.9 , the information size increased to $87.3 \%$, resulting in the cumulative $\mathrm{z}$ score touching the conventional $\alpha$ boundary of benefit $(\mathrm{P}=0.05)$ but not the trial sequential monitoring boundary of benefit (95\% confidence interval 0.85 to $1.01 ; \mathrm{D}^{2}=0 \%$ ) (online supplement). Exploratory modelling using patients who received only albumin infusion in both treatment arms of CRISTAL ${ }^{61}$ did not alter the conclusion of no mortality benefit as the cumulative $\mathrm{z}$ score crossed the futility boundary (online supplement).

Overall, with $79.9 \%$ of the required information size, the number needed to treat was 38 patients $(95 \%$ confidence interval: the number needed to treat is $>18$, and the number needed to harm is $>251$ ) for the comparison of albumin with crystalloid fluid. The overall GRADE quality of evidence was judged to be high (table $5 \Downarrow$ ).

\section{All-cause mortality with albumin compared with crystalloid fluids by risk of bias}

Figure $5 \Downarrow$ shows the analysis of predefined subgroups based on risk of bias. With exclusion of four trials at high risk studying 46 patients, 3832 patients in four trials remain (fig $6 \Downarrow$ ). The information size was 4856 . The finding of no difference between groups persists (relative risk $0.93 ; 95 \%$ confidence interval 0.86 to $1.01 ; \mathrm{P}=0.08$ ), without evidence of subgroup heterogeneity $\left(\mathrm{I}^{2}=0 \% ; \chi^{2}=1.09, \mathrm{df}=3, \mathrm{P}=0.78 ; \tau^{2}=0.00\right)$. These findings were robust to sensitivity analysis (online supplement). Clear evidence of publication bias was not evident $(\mathrm{P}=0.94)$. Trial sequential analysis reduced precision $\left(0.85\right.$ to $\left.1.02 ; \mathrm{D}^{2}=0 \%\right)$.

The cumulative $\mathrm{z}$ score moves closer to the futility boundary when trials at high risk of bias are excluded (fig $6 \Downarrow$ ). A model including RASP ${ }^{107}$ increased the information size to $91.6 \%$, but this does not alter the conclusion of no mortality benefit with albumin (online supplement). An exploratory model with CRISTAL ${ }^{61}$ including septic patients who received albumin also did not alter this conclusion, and is included only for interest, as this study is unlikely to be retained in this group after exclusion of studies at high risk of bias (online supplement).

There was no benefit with albumin observed by sepsis severity subgroups (relative risk $0.93 ; 0.85$ to $1.03 ; \mathrm{P}=0.18$ ) after exclusion of studies at high risk of bias (online supplement). The greatest trend towards possible benefit remained in the septic shock subgroup (relative risk $0.91 ; 0.81$ to $1.01 ; \mathrm{P}=0.09$ ). These findings were not altered by sensitivity analysis; albumin did not improve survival for patients with sepsis when ALBIOS $^{38}$ severe sepsis and septic shock patients were analysed in separate subgroups, and the finding was robust to trial sequential analysis (online supplement).

Overall, with $78.9 \%$ of the required information size, the number needed to treat was 37 patients (95\% confidence interval: the number needed to treat is $>18$, and the number needed to harm is to $>297$ ) for the comparison of albumin with crystalloid fluid, after excluding trials at high risk of bias. The overall GRADE quality of evidence was judged to be high (table $5 \Downarrow$ ).

\section{All-cause mortality with albumin compared with colloid fluids}

Eleven trials that randomised 299 patients compared human albumin with colloids, which were mainly hydroxyethyl starches; 36 patients were exposed to $6 \%$ tetrastarch $130 \mathrm{kDa}$, and six to gelatin. No difference was evident for all-cause mortality (relative risk $1.04 ; 95 \%$ confidence interval 0.79 to 1.38; $\mathrm{P}=0.76$ ) (fig $7 \Downarrow)$ and statistical heterogeneity was not present $\left(\mathrm{I}^{2}=0 \% ; \chi^{2}=4.47, \mathrm{df}=10, \mathrm{P}=0.92 ; \tau^{2}=0.00\right)$. The finding withstood sensitivity analysis (tables $3 \Downarrow$ and $4 \Downarrow$, plus online supplement). Clear evidence of publication bias was not present $(\mathrm{P}=0.98)$. Trial sequential analysis was not possible because the information size was too low to display a meaningful futility boundary given the required information size was 5183 .

Tables $3 \Downarrow$ and $4 \Downarrow$ (plus online supplement) summarise predefined subgroup and meta-regression analyses. The test for subgroup difference suggested a trend towards an effect of the risk of bias domain "research misconduct or duplicate publication bias" $\left(\mathrm{I}^{2}=33.0, \chi^{2}=1.49, \mathrm{df}=1, \mathrm{P}=0.22\right)$, time bias stratified by the Surviving Sepsis Campaign ${ }^{110}{ }^{111}\left(\mathrm{I}^{2}=38.1\right.$, $\chi^{2}=1.62, \mathrm{df}=1, \mathrm{P}=0.20$ ), hydroxyethyl starch (colloid) type $\left(\mathrm{I}^{2}=26.3, \chi^{2}=1.36, \mathrm{df}=1, \mathrm{P}=0.24\right)$, and disease severity (sepsis, severe sepsis, septic shock) $\left(\mathrm{I}^{2}=8.0, \chi^{2}=2.17, \mathrm{df}=1, \mathrm{P}=0.34\right)$. No survival benefit in patients with septic shock defined in different ways was observed in subgroup (relative risk 1.04; $95 \%$ confidence interval 0.79 to $1.38 ; \mathrm{P}=0.76$ ) or meta-regression analyses (table $4 \Downarrow$, online supplement).

Overall, with $5.8 \%$ of the required information size, the number needed to harm was 172 patients ( $95 \%$ confidence interval: the number needed to harm is $>9$, and the number needed to treat is $>10$ ) for the comparison of albumin with colloid fluid. The overall GRADE quality of evidence was judged to be very low (table $5 \Downarrow$ ).

\section{All-cause mortality with albumin compared with colloid fluids by risk of bias}

Three studies with 116 patients were not at high risk of bias for the comparison of human albumin with colloids (fig $7 \Downarrow$ ). No difference in mortality was detected (relative risk $0.77 ; 95 \%$ confidence interval 0.42 to $1.43 ; \mathrm{P}=0.41$ ) and statistical heterogeneity was not present $\left(\mathrm{I}^{2}=0 \% ; \chi^{2}=0.37, \mathrm{df}=2, \mathrm{P}=0.83\right.$; $\tau^{2}=0.00$ ). Sensitivity analysis did not alter this finding (tables $3 \Downarrow$ and $4 \Downarrow$, plus online supplement). Clear evidence of publication bias was lacking $(\mathrm{P}=0.61)$. Trial sequential analysis was not possible as the information size was too low.

The test for subgroup difference between studies at high risk of bias (that included 183 patients) and studies at low or unclear risk of bias was not statistically significant. A trend towards statistical heterogeneity was evident $\left(\mathrm{I}^{2}=13.4 \% ; \chi^{2}=1.15, \mathrm{df}=1\right.$; $\mathrm{P}=0.28)$. Sensitivity analysis detected low statistical heterogeneity (highest $\mathrm{I}^{2}=31.3 \%$ ) (online supplement). There were no studies with patients with septic shock (online supplement).

Overall with only $2.2 \%$ of the required information size, the number needed to treat was 10 patients ( $95 \%$ confidence interval: the number needed to treat is $>4$ and the number needed to harm is $>19$ ) for the comparison of albumin with colloid fluid, excluding studies at high risk of bias. The overall GRADE quality of evidence was judged to be low (table $5 \Downarrow$ ).

\section{Discussion}

This systematic review and meta-analysis has found that mortality in adults with sepsis, severe sepsis, and septic shock 
was not significantly reduced or increased by the use of human albumin products as part of fluid volume expansion and resuscitation (with or without improvement of baseline hypoalbuminaemia) in intensive or critical care settings. The point estimates for comparison of human albumin with control fluids (fig $3 \Downarrow$, table $5 \Downarrow$ ) suggested a potential benefit with albumin, indicating a relative risk reduction of $-7 \%$, rising to $-7.5 \%$ with exclusion of studies at high risk of bias from the analysis. For comparison with crystalloid, the point estimates were $6.8 \%$ and $7 \%$, respectively (fig $5 \Downarrow$, table $5 \Downarrow$ ). The point estimate for comparison with colloid (fig $7 \Downarrow$, table $5 \Downarrow$ ) was not in favour of human albumin indicating a relative risk increase of $1.6 \%$, but on exclusion of studies at high risk of bias the relative risk reduction was $-33.2 \%$ in favour of albumin.

However, none of these relative risk changes were statistically significant, and so only equivalence between human albumin and comparison groups can be concluded with confidence. The results are generalisable to critically unwell adults with sepsis of any severity. However, extrapolation to other clinical groups where albumin has been used or studied (patients with spontaneous bacterial peritonitis, ${ }^{12}$ children with malaria, ${ }^{22}$ or acute respiratory distress syndrome, ${ }^{95} 9698$ where the objective is fluid removal) may not be appropriate.

Trial sequential analysis corrected the $95 \%$ confidence intervals of the already non-statistically significant point estimates for each human albumin comparison fluid group to account for random error and repetitive testing of accumulating sparse data. For the comparison of albumin with control fluid, the cumulative $\mathrm{z}$ score had entered the futility area, suggesting further trials were not required (fig $4 \Downarrow$ ). When trials at high risk of bias were excluded, the curve lay just outside the futility boundary but away from both the conventional boundary of benefit $(\mathrm{P}=0.05)$ and the trial sequential monitoring boundary of benefit. This was also the case for the comparison of human albumin with crystalloid fluids, whether trials at high risk of bias were excluded or not (fig $6 \Downarrow$ ). The information size for the comparison of human albumin with colloid was too low to require futility boundaries.

An acceptable information size was achieved for the comparisons of human albumin with control and crystalloid fluids ( $85.6 \%$ and $80.5 \%$ respectively), even with exclusion of studies at high risk of bias (79.9\% and $78.9 \%$ respectively), on which to draw firm conclusions. However, for the comparison of human albumin with colloid, it was clear the information size was inadequate before (5.8\%) and after exclusion of studies at high risk of bias (2.2\%); thus firm conclusions cannot be drawn.

Overall our findings were robust to sensitivity, subgroup, meta-regression, and trial sequential analyses (tables $3 \Downarrow$ and $4 \Downarrow$, fig $4 \Downarrow$, fig $6 \Downarrow$, and online supplement). For the comparison of albumin with control fluids, improved precision $(95 \%$ confidence interval of 0.85 to $1.00 ; \mathrm{P}=0.06$ ) was observed after exclusion of studies at high risk of bias using a less appropriate fixed effects model that does not account for clinical heterogeneity. ${ }^{41}$ However, a definite signal of harm with albumin was not observed, consistent with large multicentre studies. $^{73738104}$

Our subgroup analysis by sepsis severity did not demonstrate reduced mortality with albumin for any fluid comparison when sepsis was compared to severe sepsis and septic shock (tables $3 \Downarrow$ and $4 \Downarrow$; online supplement). However, when patients with septic shock and severe sepsis were analysed in separate subgroups (by separating these groups from ALBIOS ${ }^{38}$ ), borderline statistically significant $(\mathrm{P}=0.05)$ benefit with albumin was observed overall when albumin was compared with control only after studies at high risk of bias were excluded (online supplement). Albumin was also associated with borderline $(\mathrm{P}=0.05)$ reduced mortality compared with crystalloid fluid, but statistical significance was lost when studies at high risk of bias were excluded $(\mathrm{P}=0.18)$ (online supplement). However, statistical significance of these comparisons touching the $\mathrm{P}=0.05$ boundary of benefit was not robust to correction with trial sequential analyses, with cumulative z scores crossing futility boundaries (online supplement). Furthermore, no statistically significant benefit was observed individually for any of the sepsis subgroups (including septic shock subgroups), whether studies at high risk of bias were excluded or not. For septic shock subgroups, a borderline trend was evident ( $\mathrm{P}$ values between 0.06 and 0.10$)$; the relative risk point estimates (0.91 and 0.92; online supplement) moved further in favour of albumin compared with analyses where severe sepsis was combined with septic shock (0.93 and 0.94; tables $3 \Downarrow$ and $4 \Downarrow$, online supplement). Nevertheless, the septic shock subgroups were far from the trial sequential monitoring boundary of benefit for the comparisons of albumin with control or crystalloid fluids, with or without retention of studies at high risk of bias (online supplement). No overall effect was observed for the comparison of albumin with colloid, and all studies were at high risk of bias; only 27 patients were in the septic shock subgroup.

No included sepsis randomised trial has reported a statistically significant reduction in mortality associated with albumin. All the patients recruited to EARSS had septic shock, with a median SOFA score 10, but no mortality benefit was observed at 90 days $(\mathrm{P}=0.94) \cdot{ }^{37}$ Lack of benefit at this time point $(\mathrm{P}=0.29)$ for patients with severe sepsis and septic shock with a median SOFA score of 8 was also reported in ALBIOS. ${ }^{38}$ However, in a post hoc analysis, reduced mortality $(\mathrm{P}=0.03)$ was reported for patients with septic shock at baseline based on cardiovascular SOFA score (vasopressor use), but this did not persist after adjustment for baseline imbalances of clinical relevance, including lactate $(\mathrm{P}=0.07){ }^{38}$ Survival curves for septic shock patients in both recent European multicentre studies, ${ }^{37} 38$ which infused $20 \%$ albumin and achieved improvement of hypoalbuminaemia to $>25 \mathrm{~g} / \mathrm{L}$, reported separation after around one week in favour of albumin. The lower baseline mortality of $35.1 \%$ in EARSS $^{37}$ compared with $49.3 \%$ in ALBIOS $^{38}$ might suggest a type 2 error; observed power for ALBIOS for these septic shock patients was $56.7 \%$. Thus the possibility of low information size for the subgroup of septic shock (with or without exclusion of studies at high risk of bias) in our analysis cannot be completely excluded, given the trial sequential analysis cumulative $\mathrm{z}$ scores were similarly distant from both the futility boundary and trial sequential monitoring boundary of benefit for albumin comparisons (regardless of study risk of bias; online supplement). Furthermore, SAFE also did not report mortality benefit $(\mathrm{P}=0.09)$ for patients with severe sepsis and septic shock, but baseline mortality was $35.3 \% .^{78}$ The outcome of the $438(36.0 \%)$ patients with septic shock at baseline based on cardiovascular SOFA (vasopressor use) in $\mathrm{SAFE}^{78}$ was not reported, but no difference in cardiovascular SOFA score was observed between albumin and saline treatment groups $(\mathrm{P}=0.08)$ and multivariate analysis did not detect an association with death. On this basis, we speculate that patients with septic shock probably did not benefit significantly more than those with severe sepsis. Mortality effect size in our meta-regression analysis did not detect an association with markers of baseline septic shock (vasopressor use and baseline lactate) for any fluid comparison (tables $3 \Downarrow$ and $4 \Downarrow$, online supplement). Taken together, large studies at low risk of bias that included patients with septic shock support our subgroup and meta-regression analyses of no statistically robust benefit with albumin. 
Our trial sequential analysis models showed that, even with a generous hypothetical $10 \%$ relative risk reduction in favour of albumin given to RASP, ${ }^{107}$ our principal finding of no mortality benefit would remain unchanged (online supplement). The cumulative $\mathrm{z}$ score is likely to enter the futility area with smaller relative risk reductions. The information size of the comparison of albumin with control would increase to $93.0 \%$ (87.9\% if studies at high risk of bias are excluded) and to $92.5 \%$ if compared with crystalloid (91.6\% if studies at high risk of bias are excluded). However, we await the actual primary outcome data of all-cause mortality at 28 days when the trial is completed. Exploratory models with inclusion of CRISTAL ${ }^{61}$ also did not support benefit with albumin (online supplement), particularly as the point estimate for this trial was in the direction of harm (relative risk 1.07; 95\% confidence interval 0.69 to 1.67). ${ }^{61}$ However, these are hypothesis generating models and reliable conclusions cannot be based on these analyses alone.

\section{Strengths and weaknesses in relation to other studies}

The lack of robust statistically significant survival benefit with human albumin in this analysis is consistent with large randomised trials designed to assess the outcome of all-cause mortality in comparison to crystalloid fluids, ${ }^{77} 38$ and previous meta-analyses studying adults with sepsis, ${ }^{22} 113$ or severe sepsis with or without septic shock. ${ }^{35}$ Survival advantage with human albumin for heterogeneous populations in critical or intensive care settings ${ }^{3}$ with hypoalbuminaemia or hypovolaemia has also not been demonstrated in meta-analyses of randomised clinical trials. ${ }^{4}$ Thus our analysis is consistent with published literature, and the addition of previously un-pooled 90 day mortality data from ALBIOS $^{38}$ comprising $43.2 \%$ new patient information has not altered the conclusion of no survival benefit. Our exploratory models of RASP ${ }^{107}$ and CRISTAL, ${ }^{61}$ added 976 patients for analysis that was consistent with no overall benefit (online supplement).

In contrast to our conclusion, benefit of human albumin was reported in a regression analysis of available severe sepsis patient data from SAFE. ${ }^{8}$ However, as $24.5 \%$ of patients did not have available covariate data, sampling bias may partly account for the observed benefit, which of course loses the advantages of initial randomisation. Patients in $\mathrm{SAFE}^{7}$ also did not benefit from the subsequent launch of the management guidelines from the Surviving Sepsis Campaign, ${ }^{110}{ }^{111}$ making the results difficult to generalise to current practice. A meta-analysis that combined children with malaria and adults with sepsis reported reduced mortality associated with human albumin $(\mathrm{P}=0.05) .{ }^{22}$ However, this borderline association ${ }^{23}$ was most dependent on $\mathrm{SAFE}^{7}(\mathrm{P}=0.31$ with exclusion of $\mathrm{SAFE})$ and was not robust to a random effects mode ${ }^{22}$ that considers clinical heterogeneity $(\mathrm{P}=0.08)^{114}$ nor to separate analysis of adults with sepsis (odds ratio $0.84 ; 95 \%$ confidence interval 0.69 to $1.02 ; \mathrm{P}=0.08) .^{22}$ Random error, small study effect, ${ }^{55} 56$ sparse data, and low information size are likely to have contributed to overestimation of treatment effect size in meta-analyses in critical or intensive care settings. Our analysis has overcome some of these limitations: large information size, inclusion of large recent studies, and trial sequential analysis correction for random error with accumulating data and repetitive testing. ${ }^{70-73}$

Our predefined subgroup analysis did not find a difference between hypooncotic (4-5\%) albumin and hyperoncotic (20\%) albumin for the comparisons of albumin with control, crystalloid, or colloid fluids (table $3 \Downarrow$ and online supplement). These findings are in contrast to those of CRYCO, ${ }^{115}$ a retrospective observational cohort study of 1013 patients of whom 384 had sepsis and 105 received hyperoncotic albumin, which reported increased mortality and renal morbidity. In addition a meta-analysis ${ }^{22}$ reported subgroup difference $(\mathrm{P}=0.09)$ between 383 patients who received hyperoncotic albumin and 1594 who received hypooncotic albumin. A confirmatory large randomised clinical trial is often required to confirm the results of a meta-analysis, particularly if the findings are from subgroup analyses. ${ }^{116}$ EARSS $^{37}$ and ALBIOS ${ }^{38}$ confirm that excess mortality was not observed compared with crystalloid in 2602 adults with severe sepsis and septic shock; the requirement for renal replacement therapy was also not statistically different between treatment groups.

Safety of pooled human albumin solutions has not been definitively proven in our analysis. However, trial sequential analysis with data of moderate or high GRADE quality of evidence (table $5 \Downarrow$ ) showed that for further studies to eventually show human albumin to be harmful the cumulative $\mathrm{z}$ score would have to cross the futility boundary and then the conventional boundary of harm before touching the corrected monitoring boundary of harm (figs $4 \Downarrow$ and $6 \Downarrow$ ). Supporting this notion of likely safety, SAFE recruited 6997 heterogeneous patients and reported overlapping Kaplan-Meier survival curves; and further reassurance comes from EARSS and ALBIOS. ${ }^{78} 3738$ Furthermore, reassurance of the long term safety of pooled human albumin solutions comes from serious adverse event reporting and epidemiology data, ${ }^{117} 118$ which found no deaths or transmission of viral or prion disease ${ }^{119}$ attributed to human albumin. However, the possibility cannot be completely excluded.

Inclusion of trials with inadequate follow-up may have prevented detection of a difference between groups (type 2 error). Only $\mathrm{ALBIOS}^{38}$ and $\mathrm{EARSS}^{37}$ reported 90 day mortality (table $2 \Downarrow$ ), the recommended minimum follow-up period for any clinical trial evaluating therapy for sepsis. ${ }^{39}$ However, SAFE ${ }^{78}$ hospital and 28 day mortality were the same. In our analysis there was also no subgroup heterogeneity evident for timing of mortality observation (table $3 \Downarrow$ and online supplement). Inadequate follow-up was most problematic for the comparison of albumin with colloid fluid, where all the studies were small and most reported mortality in the intensive or critical care unit (table $2 \Downarrow)$.

Our analysis of human albumin compared with colloid had relatively few patients and was dominated by studies of hydroxyethyl starch (fig $7 \Downarrow$ ). Indirectness is a limitation for this comparison in light of the recent rulings by the US Food and Drug Administration ${ }^{24}$ and European Medicines Agency ${ }^{25}$ that restrict hydroxyethyl starch use in the US and Europe, making the comparative assessment less relevant to practising healthcare professionals. The literature of hydroxyethyl starch has also been affected by over 90 retractions, ${ }^{120}{ }^{121}$ research miscount bias, time bias, and author bias (J Boldt). ${ }^{31-34}$ Four studies of 116 patients (comprising $2.8 \%$ of the patients included in this study) reported by Boldt et al met our inclusion criteria for this analysis and have not been investigated for research misconduct. ${ }^{34} \mathrm{In}$ contrast to a recent meta-analysis of hydroxyethyl starch use, ${ }^{31}$ author bias (Boldt et al) was not present in subgroup analysis (online supplement); this is consistent with a 1729 patient meta-analysis studying albumin. ${ }^{113}$ However, research misconduct and duplicate publication bias was only present in studies of hydroxyethyl starch (online supplement), and a trend towards subgroup heterogeneity, categorised as low $\left(\mathrm{I}^{2}=33.0-38.6 \%\right)$, was not found only for the comparison of albumin with crystalloid (tables $3 \Downarrow$ and $4 \Downarrow$, online supplement). Interestingly, there was also subgroup heterogeneity between 
$6 \%$ tetrastarch $130 \mathrm{kDa}$ and other hydroxyethyl starch compounds $\left(\mathrm{I}^{2}=26.3 \%\right)$, perhaps this may be partly related to time bias where heterogeneity was also present $\left(\mathrm{I}^{2}=38.1 \%\right)$. Overall, firm conclusions on comparisons of human albumin with hydroxyethyl starch, ${ }^{5}{ }^{122}$ or gelatin, another synthetic colloid of unproven efficacy and safety, ${ }^{12} 6263$ cannot be drawn because of sparse data.

\section{Implications for healthcare professionals}

We have shown that pooled human albumin solutions did not significantly reduce mortality in adults with sepsis, severe sepsis, and septic shock using currently available and emerging patient information after correction with trial sequential analysis (figs 3-7, $\downarrow \Downarrow \Downarrow \Downarrow \Downarrow$ online supplement). The possibility of marginal benefit in some sepsis severity groups, particularly septic shock, was not robust to sensitivity analyses. Our GRADE quality of evidence summary tables will assist prescribers and

policymakers (table $5 \Downarrow$ ). We have also shown that a currently registered but incomplete study $\left(\mathrm{RASP}^{107}\right)$ is unlikely to alter this finding after trial sequential analysis correction even if a $10 \%$ relative mortality benefit is eventually reported (online supplement). The safety of human albumin was implied in our analysis but cannot be concluded with total certainty: the information size for this finding was acceptable (figs $4 \Downarrow$ and $6 \Downarrow)$.

Although robust evidence for survival advantage in subgroup and meta-regression analyses was not observed with human albumin—even in patients with septic shock (tables $3 \Downarrow$ and $4 \Downarrow$; online supplement) or in studies describing early infusion, those that mandated hypoalbuminaemia as an entry criterion, or that reported improvement of hypoalbuminaemia (table

$2 \Downarrow$ )_clinicians may still choose to infuse human albumin to raise albumin levels, ${ }^{20}$ perhaps to reduce morbidity ${ }^{19}$ or for other clinical reasons not analysed here. Our meta-regression analysis did not detect a relationship with effect size of albumin exposure or serum albumin either before or after treatment (tables $3 \Downarrow$ and $4 \Downarrow$, online supplement). Direct relation to clinical patient benefit remains unclear, but other surrogate outcomes might be improved with albumin: increased colloid oncotic pressure, ${ }^{8081838687102}$ rapid achievement and maintenance of central venous pressure target, ${ }^{88}$ extracellular fluid volume expansion in excess of the infused albumin fluid volume, ${ }^{8} 3889$ greater cardiac response to fluid, ${ }^{85} 86$ cessation of vasopressors one day earlier, ${ }^{37} 38$ improvement in organ function, ${ }^{19} 38$ antioxidant function, and sustained thiol levels. ${ }^{89}{ }^{123}$. Given the considerable cost of human albumin in comparison with alternatives ${ }^{124}$ and the lack of effect on mortality, we speculate that it is unlikely the use of human albumin would be supported by a contemporary cost effectiveness analysis in the UK National Health Service, although this may not be the case for insurance based healthcare systems.

\section{Strengths and weaknesses of the study}

A major strength of this systematic review was the use of robust Cochrane methodology recommendations (although our study was not registered), ${ }^{414}$ and meta-analysis further challenged with trial sequential analysis to correct for random error and repetitive testing, which often is biased towards an intervention. ${ }^{70-73}$ Prominent focus on study bias and quality of evidence was maintained throughout the analysis using GRADE ${ }^{15}$ Publication bias and statistical heterogeneity were not present. Predefined sensitivity, subgroup, meta-regression, and trial sequential analyses that included assessment of bias and clinically relevant groups were presented to aid healthcare professionals to make clinical decisions. This analysis was performed promptly with emerging 90 day $\mathrm{ALBIOS}^{38}$ and EARSS $^{37}$ patient information on mortality outcome, comprising $62.1 \%$ of the patients within the analysis.

Subtle underlying bias of the trials included remains a possible limitation of this and any systematic review. We accounted for bias by excluding studies at high risk. However, non-statistically significant heterogeneity, categorised as low, between studies at high risk, which mainly comprised studies with research misconduct or duplicate publication bias, and those at low or unclear risk of bias, was present for the comparisons of human albumin with control or colloid fluids and represented only around 150 patients (online supplement). Clinical heterogeneity will remain within any meta-analysis (tables $1 \Downarrow$ and $2 \Downarrow$, online supplement), and we accounted for this by using the more conservative random effects model, which assumed that individual studies were estimating different but related treatment effects. The acceptable information size for the comparison of human albumin with control or crystalloid fluid provides further confidence in the findings.

\section{Unanswered questions and future research}

Human albumin solutions are manufactured from pooled plasma donations that are often presented in saline (sodium and chloride 130-160 mmol, with potassium ( $<2 \mathrm{mmol})$, sometimes trace aluminium) and have evolved over time. There is also worldwide variation between manufacturers, manufacturing standards (including pathogen inactivation and leucodepletion), use of stabilisers (caprylic acid, N-acetyl-DL-tryptophan, octanoate), with oxidation and post-translational alterations. ${ }^{125}{ }^{126}$ However, clear clinical impact of these factors has not been demonstrated. It should be noted that the effect of recombinant human albumin has not been studied in this analysis.

Our findings seem to be consistent, even with the inclusion of our models of the ongoing RASP ${ }^{107}$ or published CRISTAL ${ }^{61}$ trials, which do not show the cumulative $\mathrm{z}$ curve crossing the trial sequential monitoring boundary of benefit (online supplement). A large randomised clinical trial may be important to confirm our meta-analysis findings, perhaps in adults with septic shock. ${ }^{116}$ PRECISE $^{97} 127$ is a randomised double-blinded pilot study of early septic shock treatment with $5 \%$ albumin compared with crystalloid (saline) in emergency departments as well as critical or intensive care units; a larger follow-on trial may be registered in the future. Our analysis for the comparison of albumin with colloid fluids was small and unable to draw firm conclusions, and may benefit from further studies of available licensed synthetic colloid solutions, such as gelatin, ${ }^{12}$ which was infused into only six patients in this analysis.

\section{Conclusion}

In this analysis, human albumin solutions as part of fluid volume expansion and resuscitation for adults with sepsis of any severity (with or without baseline hypoalbuminaemia), was not effective at reducing all-cause mortality. Albumin in this setting seems to be safe, as a signal towards harm was also not detected, but this analysis does not support a recommendation for use in sepsis.

Contributors: AP had the idea, then planned and conducted the study with SJB, MAL, and UW. AP and SJB performed the literature search and selected studies, AP and UW extracted study data, AP and MAL assessed risk of bias, AP performed statistical analysis and wrote the manuscript. All authors assisted in formulation of the research question, assessed quality of evidence, contributed to and developed the final manuscript, and had full access to all of the data. 


\section{What is already known on this topic}

Pooled human albumin as part of fluid volume expansion and resuscitation is supported by the Surviving Sepsis Campaign, mainly on the basis of a 2011 meta-analysis that reported reduced mortality in children with malaria and in adults with sepsis, and a subgroup regression analysis of $75.5 \%$ of the adults with severe sepsis enrolled into the SAFE trial of 2004, in which early goal directed therapy was not part of the protocol

\section{What this study adds}

This systematic review and meta-analysis with trial sequential analysis evaluated mainly (62.1\%) new patient information on 90 day mortality from the EARRS and ALBIOS studies

As part of fluid volume expansion and resuscitation (with or without improvement of baseline hypoalbuminaemia), pooled human albumin solutions did not reduce all-cause mortality in adults with sepsis of any severity, including septic shock, in the critical or intensive care setting

A signal towards harm was not detected. GRADE quality of evidence was moderate for comparison with control fluids, high with crystalloids, and very low with colloids (mainly hydroxyethyl starch)

Funding: This research was not directly funded. AP is funded by the Medical Research Council (MRC) Chain-Florey Fellowship scheme based at the Clinical Sciences Centre, Imperial College London. All authors are supported by the National Institute for Health Research (NIHR) Biomedical Research Centre based at Imperial College Healthcare NHS Trust and Imperial College London. The views expressed are those of the authors and not necessarily those of the NHS, NIHR, or Department of Health. The research and authors are independent of funders.

Competing interests All authors have completed the ICMJE uniform disclosure form at www.icmje.org/coi_disclosure.pdf and declare: no support from any organisation for the submitted work; no financial relationships with any organisations that might have an interest in the submitted work in the previous three years; no other relationships or activities that could appear to have influenced the submitted work.

\section{Ethical approval: Not required.}

Transparency The lead author (the manuscript's guarantor) affirms that the manuscript is an honest, accurate, and transparent account of the study being reported; that no important aspects of the study have been omitted; and that any discrepancies from the study as planned (and, if relevant, registered) have been explained.

Data sharing: No additional data available.

Bunn F, Trivedi D. Colloid solutions for fluid resuscitation. Cochrane Database Syst Rev 2012;7:CD001319.

2 Jacob M, Chappell D, Conzen P, Wilkes MM, Becker BF, Rehm M. Small-volume resuscitation with hyperoncotic albumin: a systematic review of randomized clinical trials. Crit Care 2008;12:R34.

3 Perel P, Roberts I, Ker K. Colloids versus crystalloids for fluid resuscitation in critically ill patients. Cochrane Database Syst Rev 2013;2:CD000567.

4 Roberts I, Blackhall K, Alderson P, Bunn F, Schierhout G. Human albumin solution for resuscitation and volume expansion in critically ill patients. Cochrane Database Syst Rev 2011;(11):CD001208.

5 Finfer S, Liu B, Taylor C, Bellomo R, Billot L, Cook D, et al; SAFE TRIPS Investigators. Resuscitation fluid use in critically ill adults: an international cross-sectional study in 391 intensive care units. Crit Care 2010;14:R185.

6 Yim JM, Vermeulen LC, Erstad BL, Matuszewski KA, Burnett DA, Vlasses PH. Albumin and nonprotein colloid solution use in US academic health centers. Arch Intern Med 1995; 155:2450-5.

7 Finfer S, Bellomo R, Boyce N, French J, Myburgh J, Norton R; SAFE Study Investigators. A comparison of albumin and saline for fluid resuscitation in the intensive care unit. $N$ Engl J Med 2004;350:2247-56.

8 Finfer S, McEvoy S, Bellomo R, McArthur C, Myburgh J, Norton R; SAFE Study Investigators. Impact of albumin compared to saline on organ function and mortality of patients with severe sepsis. Intensive Care Med 2011;37:86-96.

9 Vincent JL, Sakr Y, Sprung CL, Ranieri VM, Reinhart K, Gerlach H, et al; Sepsis Occurrence in Acutely III Patients Investigators. Sepsis in European intensive care units: results of the SOAP study. Crit Care Med 2006;34:344-53.

10 Ranieri VM, Thompson BT, Barie PS, Dhainaut JF, Douglas IS, Finfer S, et al; PROWESS-SHOCK Study Group. Drotrecogin alfa (activated) in adults with septic shock. N Engl J Med 2012;366:2055-64.

11 Russell JA, Walley KR, Singer J, Gordon AC, Hébert PC, Cooper DJ, et al; VASST Investigators. Vasopressin versus norepinephrine infusion in patients with septic shock. N Engl J Med 2008;358:877-87.

12 Intravenous fluid therapy in adults in hospital. NICE clinical guideline 1742013 (December): www.nice.org.uk/nicemedia/live/14330/66015/15.pdf.

13 Dellinger RP, Levy MM, Rhodes A, Annane D, Gerlach H, Opal SM, et al; Surviving Sepsis Campaign Guidelines Committee including The Pediatric Subgroup. Surviving Sepsis Campaign: international guidelines for management of severe sepsis and septic shock, 2012. Intensive Care Med 2013;39:165-228. doi:10.1007/s00134-012-2769-8.

14 Dellinger RP, Levy MM, Rhodes A, Annane D, Gerlach H, Opal SM, et al; Surviving Sepsis Campaign Guidelines Committee including the Pediatric Subgroup. Surviving sepsis campaign: international guidelines for management of severe sepsis and septic shock: 2012. Crit Care Med 2013;41:580-637.

15 Guyatt GH, Oxman AD, Vist GE, Kunz R, Falck-Ytter Y, Alonso-Coello P, et al; GRADE Working Group. GRADE: an emerging consensus on rating quality of evidence and strength of recommendations. BMJ 2008;336:924-6.

16 Christopher KB, Reed GW, Nurok M, Moromizato T, Gibbons FK, Topulos GP. Change of serum albumin and risk of all-cause mortality in critical illness: a cohort study. Intensive Care Med 2012;38(suppl 1):1.

17 Artero A, Zaragoza R, Camarena JJ, Sancho S, González R, Nogueira JM. Prognostic factors of mortality in patients with community-acquired bloodstream infection with severe sepsis and septic shock. J Crit Care 2010;25:276-81.

18 Guidet B, Mosqueda GJ, Priol G, Aegerter P. The COASST study: cost-effectiveness of albumin in severe sepsis and septic shock. J Crit Care 2007;22:197-203.

19 Dubois MJ, Orellana-Jimenez C, Melot C, De Backer D, Berre J, Leeman M, et al. Albumin administration improves organ function in critically ill hypoalbuminemic patients: A prospective, randomized, controlled, pilot study. Crit Care Med 2006;34:2536-40.

20 Finfer S, Bellomo R, McEvoy S, Lo SK, Myburgh J, Neal B, et al; SAFE Study Investigators. Effect of baseline serum albumin concentration on outcome of resuscitation with albumin or saline in patients in intensive care units: analysis of data from the saline versus albumin fluid evaluation (SAFE) study. BMJ 2006;333:1044.

21 Goldwasser P, Feldman J. Association of serum albumin and mortality risk. J Clin Epidemiol 1997;50:693-703.

22 Delaney AP, Dan A, McCaffrey J, Finfer S. The role of albumin as a resuscitation fluid for patients with sepsis: a systematic review and meta-analysis. Crit Care Med 2011;39:386-91.

23 Sterne JA, Davey Smith G. Sifting the evidence-what's wrong with significance tests? BMJ 2001;322:226-31.

24 Administration UFaD. FDA Safety Communication: Boxed Warning on increased mortality and severe renal injury, and additional warning on risk of bleeding, for use of hydroxyethyl starch solutions in some settings. 2013. www.fda.gov/biologicsbloodvaccines/ safetyavailability/ucm 358271 .htm.

25 Agency EM. Hydroxyethyl-starch solutions (HES) no longer to be used in patients with sepsis or burn injuries or in critically ill patients. EMA/809470/2013 2013. www.ema. europa.eu/docs/en_GB/document_library/Referrals_document/Solutions_for_infusion containing_hydroxyethyl_starch/European_Commission_final_decision/WC500162361. pdf.

26 Patel A, Waheed U, Brett SJ. Randomised trials of $6 \%$ tetrastarch (hydroxyethyl starch $130 / 0.4$ or 0.42 ) for severe sepsis reporting mortality: systematic review and meta-analysis. Intensive Care Med 2013;39:811-22.

27 Perner A, Haase N, Guttormsen AB, Tenhunen J, Klemenzson G, Åneman A, et al; 6S Trial Group; Scandinavian Critical Care Trials Group. Hydroxyethyl starch 130/0.42 versus Ringer's acetate in severe sepsis. N Engl J Med 2012;367:124-34.

28 Schortgen F, Lacherade JC, Bruneel F, Cattaneo I, Hemery F, Lemaire F, et al. Effects of hydroxyethylstarch and gelatin on renal function in severe sepsis: a multicentre randomised study. Lancet 2001;357:911-6.

29 Gattas DJ, Dan A, Myburgh J, Billot L, Lo S, Finfer S; CHEST Management Committee. Fluid resuscitation with $6 \%$ hydroxyethyl starch (130/0.4 and 130/0.42) in acutely ill patients: systematic review of effects on mortality and treatment with renal replacement therapy. Intensive Care Med 2013;39:558-68.

30 Wiedermann CJ, Joannidis M. Increased mortality after infusion of "modern" hydroxyethyl starch. Swiss Med Wkly 2013;143:w13747.

31 Zarychanski R, Abou-Setta AM, Turgeon AF, Houston BL, McIntyre L, Marshall JC, et al. Association of hydroxyethyl starch administration with mortality and acute kidney injury in critically ill patients requiring volume resuscitation: a systematic review and meta-analysis. JAMA 2013;309:678-88.

32 Wise J. Boldt: the great pretender. BMJ 2013;346:f1738

33 Editors in chief statement regarding published clinical trials conducted without IRB approval by Joachim Boldt. 2011. www.aaeditor.org/EIC.Joint.Statement.on.Retractions.pdf.

34 Hospital L. Hospital Presents Results of Final Report: Committee Completes Investigation in the Case of Dr Boldt. 2012. www.klilu.de/content/veranstaltungen__presse/ pressearchiv/2012/hospital_presents_results_of_final_report_committee_completes investigation in the case of dr boldt/index ger.html.

35 Leitch A, Craig G, Sadler P. Human albumin solution resuscitation in severe sepsis and septic shock. J Intensive Care Soc 2013;14:45-52.

36 Farrugia A, Bansal M, Balboni S, Kimber MC, Martin GS, Cassar J. Choice of fluids in severe septic patients - a cost-effectiveness analysis informed by recent clinical trials. Rev Recent Clin Trials 2013;9:21-30.

37 Charpentier J, Mira JP, Group ES. Efficacy and tolerance of hyperoncotic albumin administration in septic shock patients: the EARSS study. Intensive Care Med 2011;37(suppl 1):S115.

38 Caironi P, Tognoni G, Masson S, Fumagalli R, Pesenti A, Romero M, et al; ALBIOS Study Investigators. Albumin replacement in patients with severe sepsis or septic shock. N Engl J Med 2014;370:1412-21. 
39 Cohen J, Guyatt G, Bernard GR, Calandra T, Cook D, Elbourne D, et al; UK Medical Research Council International Working Party. New strategies for clinical trials in patients with sepsis and septic shock. Crit Care Med 2001;29:880-6.

40 .American College of Chest Physicians/Society of Critical Care Medicine Consensus Conference: definitions for sepsis and organ failure and guidelines for the use of innovative therapies in sepsis. Crit Care Med 1992;20:864-74.

41 Higgins JPT, Green S. Cochrane handbook for systematic reviews of interventions. Version 5.1.0. Cochrane Collaboration, 2011.

42 Moher D, Liberati A, Tetzlaff J, Altman DG; PRISMA Group. Preferred reporting items for systematic reviews and meta-analyses: the PRISMA statement. BMJ 2009;339:b2535.

43 Higgins JP, Altman DG, Gøtzsche PC, Jüni P, Moher D, Oxman AD, et al; Cochrane Bias Methods Group; Cochrane Statistical Methods Group. The Cochrane Collaboration's too for assessing risk of bias in randomised trials. BMJ 2011;343:d5928.

44 Cook DJ, Guyatt GH, Ryan G, Clifton J, Buckingham L, Willan A, et al. Should unpublished data be included in meta-analyses? Current convictions and controversies. JAMA 1993;269:2749-53

45 Panagiotou OA, Contopoulos-loannidis DG, loannidis JP, Rehnborg CF. Comparative effect sizes in randomised trials from less developed and more developed countries: meta-epidemiological assessment. BMJ 2013;346:f707.

46 Onwuegbuzie AJ, Leech NL. Post hoc power: A concept whose time has come. Underst Stat 2004:3:201-30.

47 Vincent JL, Moreno R, Takala J, Willatts S, De Mendonça A, Bruining H, et al. The SOFA (Sepsis-related Organ Failure Assessment) score to describe organ dysfunction/failure. On behalf of the Working Group on Sepsis-Related Problems of the European Society of Intensive Care Medicine. Intensive Care Med 1996;22:707-10.

48 Knaus WA, Draper EA, Wagner DP, Zimmerman JE. APACHE II: a severity of disease classification system. Crit Care Med 1985;13:818-29.

49 Le Gall JR, Lemeshow S, Saulnier F. A new Simplified Acute Physiology Score (SAPS II) based on a European/North American multicenter study. JAMA 1993;270:2957-63.

50 Ranieri VM, Rubenfeld GD, Thompson BT, Ferguson ND, Caldwell E, Fan E, et al; ARDS Definition Task Force. Acute respiratory distress syndrome: the Berlin Definition. JAMA 2012;307:2526-33

51 Egger M, Davey Smith G, Schneider M, Minder C. Bias in meta-analysis detected by a simple, graphical test. BMJ 1997;315:629-34

52 Sterne JA, Gavaghan D, Egger M. Publication and related bias in meta-analysis: power of statistical tests and prevalence in the literature. J Clin Epidemiol 2000;53:1119-29.

53 Guyatt GH, Oxman AD, Kunz R, Vist GE, Falck-Ytter Y, Schünemann HJ; GRADE Working Group. What is "quality of evidence" and why is it important to clinicians?. BMJ 2008;336:995-8.

54 Thompson SG, Higgins JP. How should meta-regression analyses be undertaken and interpreted? Stat Med 2002;21:1559-73.

55 Dechartres A, Trinquart L, Boutron I, Ravaud P. Influence of trial sample size on treatment effect estimates: meta-epidemiological study. BMJ 2013;346:f2304.

56 Zhang Z, Xu X, Ni H. Small studies may overestimate the effect sizes in critical care meta-analyses: a meta-epidemiological study. Crit Care 2013;17:R2.

57 Bone RC, Balk RA, Cerra FB, Dellinger RP, Fein AM, Knaus WA, et al; The ACCP/SCCM Consensus Conference Committee. American College of Chest Physicians/Society of Critical Care Medicine. Definitions for sepsis and organ failure and guidelines for the use of innovative therapies in sepsis. Chest 1992;101:1644-55.

58 Bone RC, Balk RA, Cerra FB, Dellinger RP, Fein AM, Knaus WA, et al; ACCP/SCCM Consensus Conference Committee. Definitions for sepsis and organ failure and guidelines for the use of innovative therapies in sepsis. The ACCP/SCCM Consensus Conference Committee. American College of Chest Physicians/Society of Critical Care Medicine. 1992. Chest 2009;136(suppl):e28.

59 Haase N, Perner A, Hennings LI, Siegemund M, Lauridsen B, Wetterslev M, et al. Hydroxyethyl starch $130 / 0.38-0.45$ versus crystalloid or albumin in patients with sepsis: systematic review with meta-analysis and trial sequential analysis. BMJ 2013:346:f839.

60 Wiedermann CJ, Dunzendorfer S, Gaioni LU, Zaraca F, Joannidis M. Hyperoncotic colloids and acute kidney injury: a meta-analysis of randomized trials. Crit Care 2010;14:R191.

61 Annane D, Siami S, Jaber S, Martin C, Elatrous S, Declère AD, et al; CRISTAL Investigators. Effects of fluid resuscitation with colloids vs crystalloids on mortality in critically ill patients presenting with hypovolemic shock: the CRISTAL randomized trial. JAMA 2013:310:1809-17.

62 Thomas-Rueddel DO, Vlasakov V, Reinhart K, Jaeschke R, Rueddel H, Hutagalung R, et al. Safety of gelatin for volume resuscitation--a systematic review and meta-analysis. Intensive Care Med 2012;38:1134-42.

63 Patel A, Brett SJ. Gelatin solutions for critically unwell septic adults. Br J Hosp Med (Lond) 2013;74:657.

64 Cohen IL. Guidelines for the use of innovative therapies in sepsis. Crit Care Med 1993:21:476-7.

65 Vincent JL, Dubois MJ, Navickis RJ, Wilkes MM. Hypoalbuminemia in acute illness: is there a rationale for intervention? A meta-analysis of cohort studies and controlled trials. Ann Surg 2003;237:319-34.

66 Vincent JL, Navickis RJ, Wilkes MM. Morbidity in hospitalized patients receiving human albumin: a meta-analysis of randomized, controlled trials. Crit Care Med 2004;32:2029-38.

67 Higgins JP, Thompson SG. Quantifying heterogeneity in a meta-analysis. Stat Med 2002;21:1539-58

68 Higgins JP, Thompson SG, Deeks JJ, Altman DG. Measuring inconsistency in meta-analyses. BMJ 2003;327:557-60.

69 DerSimonian R, Laird N. Meta-analysis in clinical trials. Control Clin Trials 1986;7:177-88.

70 Thorlund K, Devereaux PJ, Wetterslev J, Guyatt G, loannidis JP, Thabane L, et al. Can trial sequential monitoring boundaries reduce spurious inferences from meta-analyses? Int J Epidemiol 2009;38:276-86.

71 Thorlund K, Engstrøm J, Wetterslev J, Brok J, Imberger G, Gluud C. User manual for trial sequential analysis (TSA). Copenhagen Trial Unit. Centre for Clinical Intervention Research, 2011

72 Wetterslev J, Thorlund K, Brok J, Gluud C. Trial sequential analysis may establish when firm evidence is reached in cumulative meta-analysis. $J$ Clin Epidemiol 2008:61:64-75.

73 Wetterslev J, Thorlund K, Brok J, Gluud C. Estimating required information size by quantifying diversity in random-effects model meta-analyses. BMC Med Res Methodol 2009;9:86

74 Boldt J, Heesen M, Müller M, Pabsdorf M, Hempelmann G. The effects of albumin versus hydroxyethyl starch solution on cardiorespiratory and circulatory variables in critically ill patients. Anesth Analg 1996;83:254-61.
75 Boldt J, Heesen M, Welters I, Padberg W, Martin K, Hempelmann G. Does the type of volume therapy influence endothelial-related coagulation in the critically ill? $\mathrm{Br} J$ Anaesth 1995;75:740-6.

76 Boldt J, Müller M, Heesen M, Heyn O, Hempelmann G. Influence of different volume therapies on platelet function in the critically ill. Intensive Care Med 1996;22:1075-81.

77 Boldt J, Muller M, Heesen M, Neumann K, Hempelmann GG. Influence of different volume therapies and pentoxifylline infusion on circulating soluble adhesion molecules in critically ill patients. Crit Care Med 1996;24:385-91.

78 Dolecek M, Svoboda P, Kantorová I, Scheer P, Sas I, Bíbrová J, et al. Therapeutic influence of $20 \%$ albumin versus $6 \%$ hydroxyethylstarch on extravascular lung water in septic patients: a randomized controlled trial. Hepatogastroenterology 2009;56:1622-8.

79 Friedman G, Jankowski S, Shahla M, Gomez J, Vincent JL. Hemodynamic effects of 6\% and $10 \%$ hydroxyethyl starch solutions versus $4 \%$ albumin solution in septic patients. $J$ Clin Anesth 2008:20:528-33.

80 Haupt MT, Rackow EC. Colloid osmotic pressure and fluid resuscitation with hetastarch albumin, and saline solutions. Crit Care Med 1982;10:159-62.

81 Metildi LA, Shackford SR, Virgilio RW, Peters RM. Crystalloid versus colloid in fluid resuscitation of patients with severe pulmonary insufficiency. Surg Gynecol Obstet 1984;158:207-12.

82 Palumbo D, Servillo G, D'Amato L, Volpe ML, Capogrosso G, De Robertis E, et al. The effects of hydroxyethyl starch solution in critically ill patients. Minerva Anestesiol 2006;72:655-64

83 Rackow EC, Falk JL, Fein IA, Siegel JS, Packman MI, Haupt MT, et al. Fluid resuscitation in circulatory shock: a comparison of the cardiorespiratory effects of albumin, hetastarch, and saline solutions in patients with hypovolemic and septic shock. Crit Care Med 1983;11:839-50.

84 Rackow EC, Mecher C, Astiz ME, Griffel M, Falk JL, Weil MH. Effects of pentastarch and albumin infusion on cardiorespiratory function and coagulation in patients with severe sepsis and systemic hypoperfusion. Crit Care Med 1989;17:394-8.

85 Trof RJ, Sukul SP, Twisk JW, Girbes AR, Groeneveld AB. Greater cardiac response of colloid than saline fluid loading in septic and non-septic critically ill patients with clinical hypovolaemia. Intensive Care Med 2010;36:697-701.

86 van der Heijden M, Verheij J, van Nieuw Amerongen GP, Groeneveld AB. Crystalloid or colloid fluid loading and pulmonary permeability, edema, and injury in septic and nonseptic critically ill patients with hypovolemia. Crit Care Med 2009;37:1275-81

87 Veneman TF, Oude Nijhuis J, Woittiez AJ. Human albumin and starch administration in critically ill patients: a prospective randomized clinical trial. Wien Klin Wochenschr 2004;116:305-9.

88 Bulanov Alu, Gorodetskiĩ VM, Shulutko EM, Vasil'ev SA, Orel EB, Malofeev VN, et al. [Effect of different colloid volume-replacing solutions on a changed hemostasis system]. Anesteziol Reanimatol 2004;(2):25-30.

89 Ernest D, Belzberg AS, Dodek PM. Distribution of normal saline and $5 \%$ albumin infusions in septic patients. Crit Care Med 1999;27:46-50.

90 Falk JL, Rackow EC, Astiz ME, Weil MH. Effects of hetastarch and albumin on coagulation in patients with septic shock. J Clin Pharmacol 1988:28:412-5.

91 Foley EF, Borlase BC, Dzik WH, Bistrian BR, Benotti PN. Albumin supplementation in the critically ill. A prospective, randomized trial. Arch Surg 1990;125:739-42.

92 Golub R, Sorrento JJ Jr, Cantu R Jr, Nierman DM, Moideen A, Stein HD. Efficacy of albumin supplementation in the surgical intensive care unit: a prospective, randomized study. Crit Care Med 1994;22:613-9.

93 Gondos T, Marjanek Z, Ulakcsai Z, Szabó Z, Bogár L, Károlyi M, et al. Short-term effectiveness of different volume replacement therapies in postoperative hypovolaemic patients. Eur J Anaesthesiol 2010;27:794-800.

94 Hondebrink Y, Jeekel L, Oude Nijhuis J, Woittiez AJJ. Restoration of colloid osmotic pressure in hypoalbuminaemic patients. Intensive Care Med 1997;23(supplement 1):S184

95 Martin GS, Mangialardi RJ, Wheeler AP, Dupont WD, Morris JA, Bernard GR. Albumin and furosemide therapy in hypoproteinemic patients with acute lung injury. Crit Care Med 2002;30:2175-82.

96 Martin GS, Moss M, Wheeler AP, Mealer M, Morris JA, Bernard GR. A randomized, controlled trial of furosemide with or without albumin in hypoproteinemic patients with acute lung injury. Crit Care Med 2005;33:1681-7.

97 Mclntyre LA, Fergusson DA, Cook DJ, Rowe BH, Bagshaw SM, Easton D, et al; Canadian Critical Care Trials Group. Fluid Resuscitation with $5 \%$ albumin versus Normal Saline in Early Septic Shock: a pilot randomized, controlled trial. J Crit Care 2012;27:e1-6.

98 Quinlan GJ, Mumby S, Martin GS, Bernard GR, Gutteridge JM, Evans TW. Albumin influences total plasma antioxidant capacity favorably in patients with acute lung injury. Crit Care Med 2004;32:755-9.

99 Rubin H, Carlson S, DeMeo M, Ganger D, Craig RM. Randomized, double-blind study of intravenous human albumin in hypoalbuminemic patients receiving total parenteral nutrition. Crit Care Med 1997:25:249-52.

100 Stockwell MA, Scott A, Day A, Riley B, Soni N. Colloid solutions in the critically ill. A randomised comparison of albumin and polygeline 2 . Serum albumin concentration and incidences of pulmonary oedema and acute renal failure. Anaesthesia 1992;47:7-9.

101 Stockwell MA, Soni N, Riley B. Colloid solutions in the critically ill. A randomised comparison of albumin and polygeline. 1. Outcome and duration of stay in the intensive care unit. Anaesthesia 1992;47:3-6.

102 Verheij J, van Lingen A, Beishuizen A, Christiaans HM, de Jong JR, Girbes AR, et al. Cardiac response is greater for colloid than saline fluid loading after cardiac or vascular surgery. Intensive Care Med 2006;32:1030-8.

103 Wojtysiak SL, Brown RO, Roberson D, Powers DA, Kudsk KA. Effect of hypoalbuminemia and parenteral nutrition on free water excretion and electrolyte-free water resorption. Crit Care Med 1992;20:164-9.

104 Finfer S, Norton R, Bellomo R, Boyce N, French J, Myburgh J. The SAFE study: saline vs. albumin for fluid resuscitation in the critically ill. Vox Sang 2004;87(Suppl 2):123-31.

105 Mayr W, Prowse C. Retraction: Finfer S, Norton R, Bellomo R, Boyce N, French J, Myburch $\mathrm{J}$, on behalf of the SAFE Study Investigators. The SAFE study: saline vs. albumin for fluid resuscitation in the critically ill. Vox Sang 2004; 87 (Suppl. 2): S123-31. 2004;87:142.

106 Timmer B, Hondebrink J, Oude Nijhuis J, Woittiez AJ. Restoration of colloid osmotic pressure in hypoalbuminaemic patients. Neth J Med 1998;52:A42.

107 Almeida A, Martin G, Hajjar L. Lactated Ringer Versus Albumin in Early Sepsis Therapy (RASP). 2013. http://clinicaltrials.gov/ct2/show/NCT01337934.

108 Wang Y, An YZ, Ma PL; China Critical Care Clinical Trial Group. Albumin for fluid resuscitation in patients with sepsis: what do we expect for? Chin Med J (Engl) 2013;126:3379-82. 
109 Bansal M, Farrugia A, Balboni S, Martin G. Relative survival benefit and morbidity with fluids in severe sepsis - a network meta-analysis of alternative therapies. Curr Drug Saf 2013;8:236-45.

110 Dellinger RP, Carlet JM, Masur H, Gerlach H, Calandra T, Cohen J, et al; Surviving Sepsis Campaign Management Guidelines Committee. Surviving Sepsis Campaign guidelines for management of severe sepsis and septic shock. Crit Care Med 2004;32:858-73.

111 Dellinger RP, Carlet JM, Masur H, Gerlach H, Calandra T, Cohen J, et al. Surviving Sepsis Campaign guidelines for management of severe sepsis and septic shock. Intensive Care Med 2004;30:536-55.

112 Salerno F, Navickis RJ, Wilkes MM. Albumin infusion improves outcomes of patients with spontaneous bacterial peritonitis: a meta-analysis of randomized trials. Clin Gastroenterol Hepatol 2013;11:123-30

113 Cui JY, Xu HL, Wang AT, Zhu X, Yao GQ, Liu F. [Influence of albumin as a resuscitation fluid on the prognosis of patients with sepsis: a Meta-analysis]. Zhongguo Wei Zhong Bing Ji Jiu Yi Xue 2012;24:18-23.

114 Thompson SG. Systematic review - why sources of heterogeneity in metaanalysis should be investigated. BMJ 1994;309:1351-5.

115 Schortgen F, Girou E, Deye N, Brochard L; CRYCO Study Group. The risk associated with hyperoncotic colloids in patients with shock. Intensive Care Med 2008:34:2157-68.

116 LeLorier J, Grégoire G, Benhaddad A, Lapierre J, Derderian F. Discrepancies between meta-analyses and subsequent large randomized, controlled trials. N Engl J Med 1997;337:536-42.

117 Vincent JL, Wilkes MM, Navickis RJ. Safety of human albumin--serious adverse events reported worldwide in 1998-2000. Br J Anaesth 2003;91:625-30.

118 von Hoegen I, Waller $\mathrm{C}$. Safety of human albumin based on spontaneously reported serious adverse events. Crit Care Med 2001;29:994-6.

119 Tabor $\mathrm{E}$. The epidemiology of virus transmission by plasma derivatives: clinical studies verifying the lack of transmission of hepatitis $B$ and $C$ viruses and HIV type 1. Transfusion 1999;39:1160-8.
120 Boldt J, Muller M, Mentges D, Papsdorf M, Hempelmann G. Retraction note: Volume therapy in the critically ill: is there a difference? Intensive Care Med 2014;40:145.

121 .Notice of formal retraction of an article by $\mathrm{Dr}$ Joachim Boldt. Br J Anaesth 2014;112:397.

122 Hartog CS, Brunkhorst FM, Bloos F, Bogatsch H, Engel C, Sengebusch K, et al. Practice of volume therapy in patients with severe sepsis: results from a nationwide sepsis prevalence study. Intensive Care Med 2010;36:553-4.

123 Quinlan GJ, Margarson MP, Mumby S, Evans TW, Gutteridge JM. Administration of albumin to patients with sepsis syndrome: a possible beneficial role in plasma thiol repletion. Clin Sci (Lond) 1998;95:459-65.

124 British National Formulary (BNF) . 65 ed. BMJ Group, Pharmaceutical Press, 2013.

125 Bar-Or D, Bar-Or R, Rael LT, Gardner DK, Slone DS, Craun ML. Heterogeneity and oxidation status of commercial human albumin preparations in clinical use. Crit Care Med 2005;33:1638-41.

126 Matejtschuk P, Dash CH, Gascoigne EW. Production of human albumin solution: a continually developing colloid. Br J Anaesth 2000;85:887-95.

127 Mclntyre L, Fergusson DA, Rowe B, Cook DJ, Arabi Y, Bagshaw SM, et al; Canadian Critical Care Trials Group. The PRECISE RCT: evolution of an early septic shock fluid resuscitation trial. Transfus Med Rev 2012;26:333-41.

\section{Accepted: 20 June 2014}

\section{Cite this as: BMJ 2014;349:g4561}

This is an Open Access article distributed in accordance with the Creative Commons Attribution Non Commercial (CC BY-NC 3.0) license, which permits others to distribute, remix, adapt, build upon this work non-commercially, and license their derivative works on different terms, provided the original work is properly cited and the use is non-commercial. See: http://creativecommons.org/licenses/by-nc/3.0/. 


\section{Tables}

Table 1| Characteristics of 16 randomised critical care studies reported in 18 articles included in meta-analysis, and baseline patient characteristics of the albumin intervention group (or study population). Further study information available in data supplement

\begin{tabular}{|c|c|c|c|c|c|c|c|}
\hline \multirow[b]{2}{*}{ Study } & \multirow[b]{2}{*}{ Study characteristics } & \multirow[b]{2}{*}{ Diagnosis } & \multirow{2}{*}{$\begin{array}{l}\text { No of } \\
\text { patients (\% } \\
\text { male) }\end{array}$} & \multicolumn{4}{|c|}{ Baseline characteristics of patients in albumin intervention group } \\
\hline & & & & Age (years) & $\begin{array}{l}\text { Serum lactate } \\
\text { level }(\mathrm{mmol} / \mathrm{L})\end{array}$ & $\begin{array}{l}\text { Vasopressor } \\
\text { use (\%) }\end{array}$ & $\begin{array}{l}\text { Serum albumin } \\
\text { level }(g / L)\end{array}$ \\
\hline ALBIOS $2014^{38}$ & $\begin{array}{l}100 \text { centres; Italy; Aug } \\
2008 \text { to Feb } 2012\end{array}$ & $\begin{array}{l}\text { Severe sepsis; } \\
\text { septic shock }\end{array}$ & $1810(60.1)$ & $\begin{array}{c}\text { Median } 70.0 \text { (IQR } \\
57-77)\end{array}$ & $\begin{array}{c}\text { Median } 2.3 \text { (IQR } \\
1.4-4.2)\end{array}$ & 62.6 & Mean $24.1(6.3)$ \\
\hline Boldt et al $1995^{75}$ & 1 centre; Germany & Sepsis* $^{*}$ & 30 & $\begin{array}{c}\text { Median } 59.3 \text { (range } \\
40-74 \text { ) }\end{array}$ & - & - & - \\
\hline $\begin{array}{l}\text { Boldt, Heesen, et al } \\
1996^{74}\end{array}$ & 1 centre; Germany & Sepsis $^{*}$ & 30 & Mean 54.8 (SD 10.8) & Mean 1.7 (SD 0.4) & 21.4 & - \\
\hline $\begin{array}{l}\text { Boldt, Müller, et al } \\
1996^{76}\end{array}$ & 1 centre; Germany & Sepsis $^{*}$ & $28(64.3)$ & Mean 57.5 (SD 12.3) & - & 85.7 & - \\
\hline $\begin{array}{l}\text { Boldt, Muller, et al } \\
1996^{77}\end{array}$ & 1 centre; Germany & Sepsis* & 28 & Mean $61.0($ SD 10.1) & - & 53.3 & - \\
\hline Dolecek et al $2009^{78}$ & $\begin{array}{c}1 \text { centre; Czech } \\
\text { Republic; May } 2005 \text { to } \\
\text { Feb } 2008\end{array}$ & Severe sepsis $†$ & $56(86.7)$ & $\begin{array}{c}\text { Median } 47.0 \text { (range } 19 \\
\text { to } 81 \text { ) }\end{array}$ & - & 60.0 & $\begin{array}{c}\text { Mean } 23.8(\mathrm{SD} \\
5.9)\end{array}$ \\
\hline EARSS $2011^{37}$ & $\begin{array}{l}29 \text { centres; France; Jul } \\
2006 \text { to Mar } 2010\end{array}$ & Septic shock & $792(65.7)$ & $\begin{array}{c}\text { Median 66.0 (IQR } \\
55-76)\end{array}$ & $\begin{array}{c}\text { Median } 0.2 \text { (IQR } \\
0.2-0.4)\end{array}$ & 100 & $\begin{array}{c}\text { Median } 17.8 \text { (IQR } \\
14-12)\end{array}$ \\
\hline Friedman et al $2008^{79}$ & 1 centre; Belgium & Sepsis & $42(38.4)$ & Mean 66.0 (SD 14) & - & 84.6 & - \\
\hline Haupt et al $1982^{80}$ & 1 centre; USA & Septic shock & $17(71.4)$ & Mean 76.0 (SD 12.8) & Mean 6.6 (SD 6.0) & 100 & - \\
\hline Metildi et al $1984^{81}$ & $\begin{array}{l}1 \text { centre; USA; Jun } 1978 \\
\text { to May } 1979\end{array}$ & Severe sepsis $\ddagger$ & $24(66.7)$ & Mean 45.0 (SD 20.5) & - & - & - \\
\hline Palumbo et al $2006^{82}$ & 1 centre; Italy & $\begin{array}{l}\text { Severe sepsis; } \\
\text { septic shock }\end{array}$ & $20(50.0)$ & Mean 59.6 (SD 12.6)§ & - & - & - \\
\hline Rackow et al $1983^{83}$ & $\begin{array}{c}1 \text { centre; USA; Oct } 1979 \\
\text { to Jun } 1980\end{array}$ & Septic shock & $18(71.4)$ & Mean 76.0 (SD 12.8) & Mean 6.0 (SD 1.8)§ & 100 & - \\
\hline Rackow et al $1989^{84}$ & 1 centre; USA & Severe sepsis & $20(80.0)$ & Mean 65.1 (SD 13) & Mean 5.6 (SD 1.4) & - & - \\
\hline SAFE $2004^{7}, 2011^{8}$ & $\begin{array}{l}16 \text { centres; Australasia; } \\
\text { Nov } 2001 \text { to Jun } 2003\end{array}$ & $\begin{array}{l}\text { Severe sepsis; } \\
\text { septic shock }\end{array}$ & $1218(59.6)$ & Mean 60.5 (SD 17.2) & - & 34.8 & $\begin{array}{c}\text { Mean 25.0 (SD } \\
7.2)\end{array}$ \\
\hline $\begin{array}{l}\text { Van der Heijden et al } \\
2009^{86}, \text { Trof et al } \\
2010^{0^{5}}\end{array}$ & 1 centre; Netherlands & Severe sepsis & $24(66.7)$ & Mean 60.0 (SD 9) & Mean 2.0 (SD 0.9) & $67.0 \S$ & Mean 11 (SD 2) \\
\hline Veneman et al $2004^{87}$ & 1 centre; Netherlands & Severe sepsis & $33(27) \rrbracket ; 53.3 \S$ & Mean $72.0 \S$ & $\begin{array}{c}\text { Mean } 1.3(\mathrm{SD} \\
40.2) \S\end{array}$ & $50.0 \S$ & Mean 15 (SD 1)§ \\
\hline
\end{tabular}

IQR=interquartile range; $\mathrm{SD}=$ standard deviation; - =value unclear or not reported.

*Patients with septic shock excluded.

†Extravascular lung water $>7 \mathrm{~mL} / \mathrm{kg}$.

$\ddagger$ Moderate to severe acute respiratory distress syndrome.

§Data from study population.

ISepsis group patients originally reported ${ }^{87}$ at odds with data supplied by the authors. ${ }^{22}$ 
Table 2| Details of interventions used and outcomes measured in the 16 randomised critical care studies (reported in 18 articles) included in meta-analysis. Further study information available in online data supplement

\begin{tabular}{|c|c|c|c|c|c|c|c|c|}
\hline \multirow[b]{2}{*}{ Study } & \multicolumn{4}{|c|}{ Characteristics of fluid treatment interventions } & \multicolumn{4}{|c|}{ Outcomes } \\
\hline & Albumin (\%) & Control fluid(s) & $\begin{array}{l}\text { Intervention } \\
\text { period } \\
\text { (days) }\end{array}$ & $\begin{array}{l}\text { Daily } \\
\text { albumin } \\
\text { dose }(g)\end{array}$ & $\begin{array}{l}\text { Mean (SD) } \\
\text { serum } \\
\text { albumin level } \\
\leq 24 \text { hours } \\
\text { after } \\
\text { intervention } \\
\text { (g/L) }\end{array}$ & $\begin{array}{c}\text { Final } \\
\text { mortality } \\
\text { observation } \\
\text { (days) }\end{array}$ & $\begin{array}{c}\% \text { baseline } \\
\text { mortality, } v(a) \\
\text { control, }(b) \\
\text { crystalloid, }(c) \\
\text { HES, }(d) \text { gelatin }\end{array}$ & $\begin{array}{c}\% \text { observed } \\
\text { power } v(a) \\
\text { control, }(b) \\
\text { crystalloid, }(c) \\
\text { HES, }(d) \text { gelatin }\end{array}$ \\
\hline ALBIOS $2014^{38}$ & $\begin{array}{l}\text { 20; predefined } \\
\text { dose }\end{array}$ & Crystalloid & $9^{*}$ & 24.2 & $28.6(5.4)$ & 90 & (a) 42.9 & (a) 18.5 \\
\hline Boldt et al $1995^{75}$ & 20; variable dose & Colloid (HES†) & 5 & 70 & - & ICU & (a) 66.7 & (a) 1.1 \\
\hline $\begin{array}{l}\text { Boldt, Heesen, et } \\
\text { al } 1996^{74}\end{array}$ & 20¥; variable dose & Colloid (HES†) & 5 & 84.4 & - & ICU & (a) 26.7 & (a) 5.5 \\
\hline $\begin{array}{l}\text { Boldt, Müller, et al } \\
1996^{76}\end{array}$ & 20 ; variable dose & Colloid (HES†) & 5 & 71.6 & - & ICU & (a) 35.7 & (a) 5.6 \\
\hline $\begin{array}{l}\text { Boldt, Muller, et al } \\
1996^{77}\end{array}$ & 20; variable dose & Colloid (HES†) & 5 & 101 & - & ICU & (a) 21.4 & (a) 22.2 \\
\hline $\begin{array}{l}\text { Dolecek et al } \\
2009^{78}\end{array}$ & $\begin{array}{l}\text { 20§; predefined } \\
\text { dose }\end{array}$ & Colloid (HESI) & 3 & 40 & - & 28 & (a) 13.3 & (a) 15.4 \\
\hline EARSS $2011^{37}$ & $\begin{array}{c}20^{* *} ; \text { predefined } \\
\text { dose }\end{array}$ & $\begin{array}{c}\text { Crystalloid }(0.9 \% \\
\text { saline })\end{array}$ & 3 & 60 & $\sim 24$ & 90 & (a) 35.1 & (a) 2.3 \\
\hline $\begin{array}{l}\text { Friedman et al } \\
2008^{79}\end{array}$ & $\begin{array}{l}4 \uparrow+\text {; predefined } \\
\text { dose }\end{array}$ & Colloid (HES $\ddagger$ ) & 0.03 & 16 & - & Hospital & (a) 37 & (a) 3.9 \\
\hline Haupt et al $1982^{80}$ & $5 \S \S ;$ variable dose & $\begin{array}{c}\text { Crystalloid }(0.9 \% \\
\text { saline§§); colloid } \\
\text { (HES } \mid \text { I) }\end{array}$ & 1 & $155^{\star \star *}$ & - & Hospital & $\begin{array}{c}\text { (a) } 61.5,(b) 75.0 \\
\text { (c) } 50.0\end{array}$ & $\begin{array}{c}\text { (a) } 5.9,(b) 2.4 \text {, } \\
\text { (c) } 11.5\end{array}$ \\
\hline Metildi et al $1984^{81}$ & 5 ; variable dose & $\begin{array}{c}\text { Crystalloid (Ringer's } \\
\text { lactate) }\end{array}$ & 2 & $85^{\star \star \star}$ & - & Hospital & (a) 91.7 & (a) 8.7 \\
\hline $\begin{array}{l}\text { Palumbo et al } \\
2006^{82}\end{array}$ & $20 ;$ variable dose & Colloid (HESף) & -; 5 & - & - & -; 5 & (a) 30 & (a) 6.4 \\
\hline $\begin{array}{l}\text { Rackow et al } \\
1983^{83}\end{array}$ & $5 \S \S ;$ variable dose & $\begin{array}{c}\text { Crystalloid }(0.9 \% \\
\text { saline§§); colloid } \\
\text { (HESףף) }\end{array}$ & 1 & $141^{\star \star *}$ & - & Hospital & $\begin{array}{c}\text { (a) } 60.0,(b) 75.0 \\
\text { (c) } 50.0\end{array}$ & $\begin{array}{c}\text { (a) } 10.3,(b) 2.4 \\
\text { (c) } 17.9\end{array}$ \\
\hline $\begin{array}{l}\text { Rackow et al } \\
1989^{84}\end{array}$ & $5 \S \S ;$ variable dose & Colloid (HES†††) & 0.03 & 49 & - & Hospital & (a) 50 & (a) 1.1 \\
\hline $\begin{array}{l}\text { SAFE } 2004^{7}, \\
2011^{8}\end{array}$ & $\begin{array}{c}\text { 4¥¥¥; variable } \\
\text { dose }\end{array}$ & $\begin{array}{c}\text { Crystalloid }(0.9 \% \\
\text { saline })\end{array}$ & 8.2 & 31.7 & $\sim 26$ & 28 & (a) 35.3 & (a) 40 \\
\hline $\begin{array}{l}\text { Van der Heijden } \\
\text { et al } 2009^{86} \text {, Trof } \\
\text { et al } 2010^{85}\end{array}$ & $\begin{array}{c}5 \S \S \S ; \text { variable } \\
\text { dose }\end{array}$ & $\begin{array}{c}\text { Crystalloid }(0.9 \% \\
\text { saline); colloids } \\
\text { (HES IIף; } \\
\left.\text { gelatin }^{* \star * *}\right)\end{array}$ & 0.06 & 300 & $27(3)$ & ICU & $\begin{array}{l}\text { (a) } 38.9,(b) 33.3 \\
\text { (c) } 50.0,(d) 33.3\end{array}$ & $\begin{array}{l}\text { (a) 2.3, (b) 1.1, } \\
\text { (c) 8.0, (d) } 1.1\end{array}$ \\
\hline $\begin{array}{l}\text { Veneman et al } \\
2004^{87}\end{array}$ & $\begin{array}{c}20 \dagger \uparrow \dagger \dagger ; \\
\text { predefined dose }\end{array}$ & $\begin{array}{l}\text { Crystalloid }(0.9 \% \\
\text { saline); colloid } \\
\text { (HES } \ddagger \ddagger \ddagger \ddagger)\end{array}$ & 3 & 60 & - & 30 & (a) 56 & (a) 4.6 \\
\hline
\end{tabular}

$\mathrm{SD}=$ standard deviation; ICU=intensive or critical care unit; HES=hydroxyethyl starch; - =value unclear or not reported; =value estimated from a graph.

${ }^{*} \leq 28$ days, median presented.

† $10 \%$ pentastarch $200 \mathrm{kDa}$.

‡ Sartorius membrane $20 \mathrm{kDa}$.

$\S$ Immuno, Baxter.

I $6 \%$ tetrastarch $130 \mathrm{kDa}$ (Voluven, Fresenius-Kabi).

** Vialebex, LFB.

†† Red Cross of Belgium.

㧊 $6 \%$ or $10 \%$ pentastarch $200 \mathrm{kDa}$ (HAES-steril; Fresenius).

$\S \S$ Cutter.

ๆๆ 6\% hetastarch (Hespan, American Critical Care)

*** Data from study population.

††† 10\% pentastarch (Dupont Critical Care).

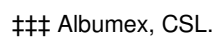

$\S \S \S$ Cealb, Sanquin. 
Table 2 (continued)

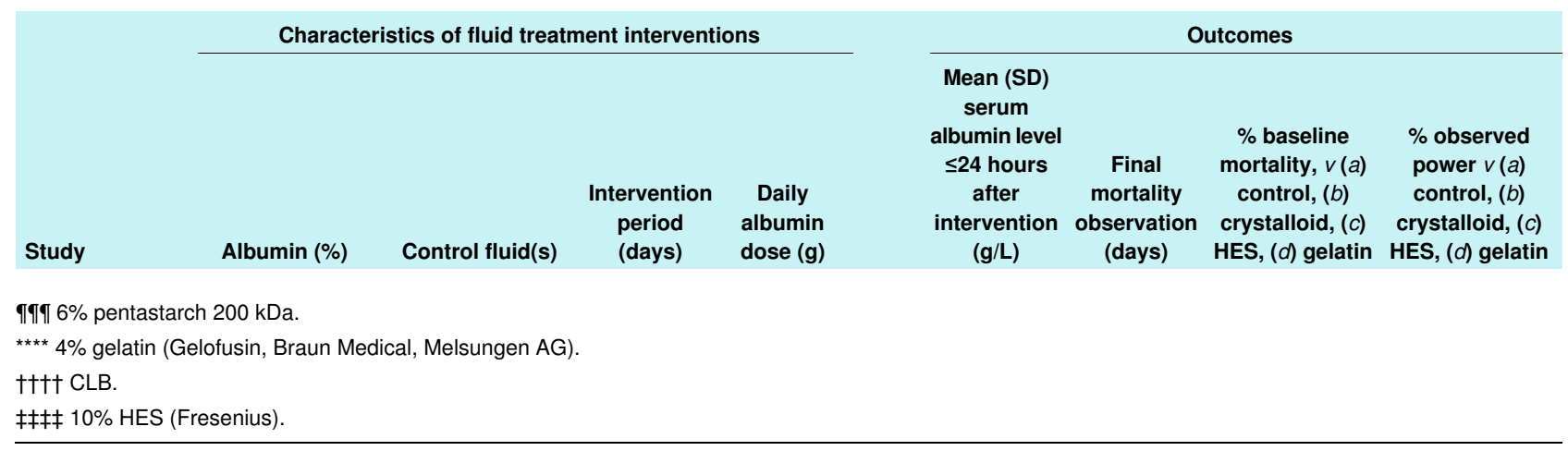


Table 3| Predefined clinical subgroup analysis with relative risk effect size measure using a random effects model (Mantel-Haenszel) and precision for the comparisons of albumin with control, crystalloid, and colloid fluid (see online supplement for a more comprehensive version of this table that includes predefined sensitivity and bias subgroup analyses)

\begin{tabular}{|c|c|c|c|c|c|c|c|c|c|}
\hline \multirow[b]{2}{*}{ Category } & \multirow[b]{2}{*}{ Subgroups } & \multirow{2}{*}{$\begin{array}{l}\text { No of } \\
\text { studies }\end{array}$} & \multirow{2}{*}{$\begin{array}{c}\text { No of } \\
\text { patients }\end{array}$} & \multirow[b]{2}{*}{ Point estimate $(95 \% \mathrm{Cl})$} & \multirow[b]{2}{*}{$P$ value } & \multicolumn{2}{|c|}{ Group heterogeneity } & \multicolumn{2}{|c|}{ Subgroup difference } \\
\hline & & & & & & $I^{2}$ & $\mathrm{X}^{2} \mathrm{P}$ value & $\mathbf{I}^{2}$ & $\chi^{2} P$ value \\
\hline \multicolumn{10}{|c|}{ Human albumin compared with control fluid } \\
\hline \multirow{2}{*}{$\begin{array}{l}\text { Disease } \\
\text { severity (sepsis } \\
v \text { severe sepsis } \\
\text { and/or septic } \\
\text { shock) }\end{array}$} & $\begin{array}{l}\text { Severe sepsis and/or septic } \\
\text { shock }\end{array}$ & 11 & 3854 & $0.94(0.87$ to 1.01$)$ & 0.09 & 0 & 0.96 & 0 & 0.55 \\
\hline & Sepsis & 5 & 336 & $1.15(0.73$ to 1.51$)$ & 0.80 & 0 & 0.79 & NA & NA \\
\hline \multirow{4}{*}{$\begin{array}{l}\text { Disease } \\
\text { severity (sepsis } \\
v \text { severe sepsis } \\
v \text { septic shock) }\end{array}$} & All studies & 16 & 4190 & $0.94(0.87$ to 1.01$)$ & 0.08 & 0 & 0.88 & 0 & 0.76 \\
\hline & Septic shock & 4 & 1962 & $0.92(0.83$ to 1.02$)$ & 0.10 & 0 & 0.45 & NA & NA \\
\hline & Severe sepsis & 8 & 2070 & $0.95(0.85$ to 1.06$)$ & 0.35 & 0 & 0.67 & NA & NA \\
\hline & Sepsis & 5 & 336 & $1.15(0.73$ to 1.51$)$ & 0.80 & 0 & 0.79 & NA & NA \\
\hline \multirow{2}{*}{$\begin{array}{l}\text { Intervention } \\
\text { method }\end{array}$} & Predefined & 4 & 2691 & 0.95 (0.87 to 1.05$)$ & 0.31 & 0 & 0.77 & 0 & 0.64 \\
\hline & Variable & 16 & 1499 & $0.92(0.81$ to 1.04$)$ & 0.18 & 0 & 0.96 & NA & NA \\
\hline \multirow{2}{*}{$\begin{array}{l}\text { Intervention } \\
\text { type }\end{array}$} & Hypooncotic (4-5\% albumin) & 7 & 1363 & $0.90(0.79$ to 1.03$)$ & 0.13 & 0 & 0.92 & 0 & 0.47 \\
\hline & Hyperoncotic ( $20 \%$ albumin) & 9 & 2827 & $0.96(0.87$ to 1.05$)$ & 0.35 & 0 & 0.92 & NA & NA \\
\hline \multirow{2}{*}{$\begin{array}{l}\text { Intervention } \\
\text { timing }\end{array}$} & Early (<24 hours) & 6 & 3907 & $0.93(0.86$ to 1.01$)$ & 0.10 & 0 & 0.89 & 0 & 0.69 \\
\hline & Not described/other timing & 10 & 283 & $0.98(0.80$ to 1.20$)$ & 0.82 & 0 & 0.93 & NA & NA \\
\hline \multirow{4}{*}{$\begin{array}{l}\text { Time of } \\
\text { mortality } \\
\text { observation }\end{array}$} & 90 day & 2 & 2602 & 0.95 (0.87 to 1.05$)$ & 0.32 & 0 & 0.69 & 0 & 0.72 \\
\hline & 28-30 day & 3 & 1307 & 0.88 (0.75 to 1.02$)$ & 0.09 & 0 & 0.58 & NA & NA \\
\hline & Hospital & 5 & 122 & 0.99 (0.78 to 1.26$)$ & 0.96 & 0 & 0.80 & NA & NA \\
\hline & $\mathrm{ICU}$ & 6 & 160 & $1.03(0.72$ to 1.48$)$ & 0.88 & 0 & 0.86 & NA & NA \\
\hline
\end{tabular}

Human albumin compared to crystalloid fluid

\begin{tabular}{|c|c|c|c|c|c|c|c|c|c|}
\hline \multirow{2}{*}{$\begin{array}{l}\text { Disease } \\
\text { severity (sepsis } \\
\text { v severe sepsis } \\
\text { and/or septic } \\
\text { shock) }\end{array}$} & $\begin{array}{c}\text { Severe sepsis and/or septic } \\
\text { shock }\end{array}$ & 7 & 3878 & $0.93(0.86$ to 1.01$)$ & 0.07 & 0 & 0.98 & NA & NA \\
\hline & Sepsis & 0 & 0 & NA & NA & NA & NA & NA & NA \\
\hline \multirow{4}{*}{$\begin{array}{l}\text { Disease } \\
\text { severity (sepsis } \\
v \text { severe sepsis } \\
v \text { septic shock) }\end{array}$} & All studies & 7 & 3878 & $0.93(0.86$ to 1.00 & 0.05 & 0 & 0.63 & 0 & 0.56 \\
\hline & Septic shock & 4 & 1949 & 0.91 (0.82 to 1.01 & 0.06 & 0 & 0.77 & NA & NA \\
\hline & Severe sepsis & 4 & 1929 & $0.96(0.83$ to 1.10$)$ & 0.55 & 0 & 0.29 & NA & NA \\
\hline & Sepsis & 0 & 0 & NA & NA & NA & NA & NA & NA \\
\hline \multirow{2}{*}{$\begin{array}{l}\text { Intervention } \\
\text { method }\end{array}$} & Predefined & 2 & 2602 & 0.95 (0.87 to 1.05$)$ & 0.32 & 0 & 0.69 & 0 & 0.32 \\
\hline & Variable & 5 & 1276 & 0.88 (0.77 to 1.01$)$ & 0.08 & 0 & 1.00 & NA & NA \\
\hline \multirow{2}{*}{$\begin{array}{l}\text { Intervention } \\
\text { type }\end{array}$} & Hypooncotic (4-5\% albumin) & 5 & 1276 & $0.88(0.77$ to 1.01$)$ & 0.08 & 0 & 1.00 & 0 & 0.33 \\
\hline & Hyperoncotic (20\% albumin) & 2 & 2602 & 0.95 (0.87 to 1.05$)$ & 0.32 & 0 & 0.69 & NA & NA \\
\hline \multirow{2}{*}{$\begin{array}{l}\text { Intervention } \\
\text { timing }\end{array}$} & Early (<24 hours) & 4 & 3832 & $0.93(0.86$ to 1.01$)$ & 0.12 & 0 & 0.78 & 0 & 0.93 \\
\hline & Not described/other timing & 3 & 46 & $0.92(0.71$ to 1.20$)$ & 0.53 & 0 & 0.99 & NA & NA \\
\hline \multirow{4}{*}{$\begin{array}{l}\text { Time of } \\
\text { mortality } \\
\text { observation }\end{array}$} & 90 day & 2 & 2602 & 0.95 (0.87 to 1.05$)$ & 0.32 & 0 & 0.69 & 0 & 0.82 \\
\hline & 28-30 day & 1 & 1218 & 0.87 (0.74 to 1.02$)$ & 0.09 & NA & NA & NA & NA \\
\hline & Hospital & 3 & 46 & $0.92(0.71$ to 1.20$)$ & 0.53 & 0 & 0.99 & NA & NA \\
\hline & ICU & 1 & 12 & $1.00(0.20$ to 4.95$)$ & 1.00 & NA & NA & NA & NA \\
\hline \multicolumn{10}{|c|}{ Human albumin compared to colloid fluid } \\
\hline \multirow{2}{*}{$\begin{array}{l}\text { Disease } \\
\text { severity (sepsis } \\
\text { vsevere sepsis } \\
\text { and/or septic } \\
\text { shock) }\end{array}$} & $\begin{array}{c}\text { Severe sepsis and/or septic } \\
\text { shock }\end{array}$ & 7 & 141 & $1.04(0.68$ to 1.59$)$ & 0.86 & 0 & 0.71 & 0 & 0.98 \\
\hline & Sepsis & 5 & 158 & 1.05 (0.73 to 1.51$)$ & 0.80 & 0 & 0.79 & NA & NA \\
\hline \multirow{4}{*}{$\begin{array}{l}\text { Disease } \\
\text { severity (sepsis } \\
v \text { severe sepsis } \\
v \text { septic shock) }\end{array}$} & All studies & 11 & 299 & $1.04(0.79$ to 1.38$)$ & 0.76 & 0 & 0.92 & 8.0 & 0.34 \\
\hline & Septic shock & 2 & 27 & $1.54(0.78$ to 3.01$)$ & 0.21 & 0 & 0.82 & NA & NA \\
\hline & Severe sepsis & 4 & 114 & $0.80(0.46$ to 1.39$)$ & 0.43 & 0 & 0.90 & NA & NA \\
\hline & Sepsis & 5 & 158 & $1.05(0.73$ to 1.51$)$ & 0.80 & 0 & 0.79 & NA & NA \\
\hline
\end{tabular}




\section{Table 3 (continued)}

\begin{tabular}{|c|c|c|c|c|c|c|c|c|c|}
\hline \multirow[b]{2}{*}{ Category } & \multirow[b]{2}{*}{ Subgroups } & \multirow{2}{*}{$\begin{array}{c}\text { No of } \\
\text { studies }\end{array}$} & \multirow{2}{*}{$\begin{array}{c}\text { No of } \\
\text { patients }\end{array}$} & \multirow[b]{2}{*}{ Point estimate $(95 \% \mathrm{Cl})$} & \multirow[b]{2}{*}{$P$ value } & \multicolumn{2}{|c|}{ Group heterogeneity } & \multicolumn{2}{|c|}{ Subgroup difference } \\
\hline & & & & & & $I^{2}$ & $X^{2} P$ value & $\mathbf{I}^{2}$ & $\chi^{2} P$ value \\
\hline \multirow{2}{*}{$\begin{array}{l}\text { Intervention } \\
\text { method }\end{array}$} & Predefined & 2 & 98 & 0.77 (0.38 to 1.53$)$ & 0.45 & 0 & 0.54 & 0 & 0.34 \\
\hline & Variable & 9 & 201 & $1.11(0.82$ to 1.50$)$ & 0.51 & 0 & 0.92 & NA & NA \\
\hline \multirow{2}{*}{$\begin{array}{l}\text { Intervention } \\
\text { type }\end{array}$} & Hypooncotic (4-5\% albumin) & 5 & 107 & $1.13(0.74$ to 1.74$)$ & 0.57 & 0 & 0.83 & 0 & 0.62 \\
\hline & Hyperoncotic ( $20 \%$ albumin) & 6 & 192 & 0.99 (0.69 to 1.41$)$ & 0.94 & 0 & 0.74 & NA & NA \\
\hline \multirow{5}{*}{$\begin{array}{l}\text { Intervention } \\
\text { timing }\end{array}$} & Early (<24 hours) & 2 & 48 & 1.04 (0.45 to 2.42$)$ & 0.93 & 0 & 0.61 & 0 & 0.99 \\
\hline & Not described/other timing & 9 & 251 & $1.05(0.78$ to 1.40$)$ & 0.77 & 0 & 0.84 & NA & NA \\
\hline & 28-30 day & 1 & 56 & 0.58 (0.18 to 1.83$)$ & 0.35 & NA & NA & NA & NA \\
\hline & Hospital & 4 & 89 & $1.18(0.75$ to 1.86$)$ & 0.47 & 0 & 0.76 & NA & NA \\
\hline & ICU & 6 & 154 & $1.02(0.71$ to 1.47$)$ & 0.90 & 0 & 0.85 & NA & NA \\
\hline \multirow{2}{*}{$\begin{array}{l}\text { Colloid type: } \\
\text { HES }\end{array}$} & $6 \%$ tetrastarch $130 \mathrm{kDa}$ & 2 & 76 & $0.65(0.28$ to 1.51$)$ & 0.32 & 0 & 0.76 & 26.3 & 0.24 \\
\hline & Other & 9 & 223 & $1.11(0.83$ to 1.48$)$ & 0.50 & 0 & 0.93 & NA & NA \\
\hline $\begin{array}{l}\text { Colloid type: } \\
\text { gelatin }\end{array}$ & Gelatin & 1 & 12 & $1.00(0.20$ to 4.95$)$ & 1 & NA & NA & NA & NA \\
\hline
\end{tabular}

$\mathrm{NA}=$ not applicable. $\mathrm{ICU}=$ intensive or critical care unit. $\mathrm{HES}=$ hydroxyethyl starch. 
Table 4| Mixed effect meta-regression (unrestricted maximum likelihood) slope effect size, precision, and heterogeneity for the comparisons of albumin with control, crystalloid, and colloid fluid (see online supplement for a more comprehensive version of this table that includes predefined sensitivity and bias subgroup analyses)

\begin{tabular}{|c|c|c|c|c|c|c|}
\hline Category & Covariate & No of studies & No of patients & Point estimate $(95 \% \mathrm{Cl})$ & $P$ value & $\tau^{2}$ \\
\hline \multicolumn{7}{|c|}{ Human albumin compared with control fluid } \\
\hline Baseline mortality risk & Comparison group mortality & 16 & 4190 & $0.0007(-0.0046$ to 0.0061$)$ & 0.79 & 0 \\
\hline Baseline septic shock & Vasopressor use & 12 & 4096 & $0.0018(-0.0177$ to 0.0544$)$ & 0.32 & 0 \\
\hline Baseline septic shock & Lactate & 8 & 2742 & $0.0136(-0.0589$ to 0.0860$)$ & 0.71 & 0 \\
\hline Baseline hypoalbuminaemia & Baseline albumin level & 6 & 3933 & $-0.0124(-0.0407$ to 0.0159$)$ & 0.39 & 0 \\
\hline Daily intervention exposure & Daily albumin dose & 15 & 4170 & $0.0013(-0.0013$ to 0.0038$)$ & 0.33 & 0 \\
\hline Total intervention exposure & Total albumin dose & 15 & 4170 & $0.0006(-0.0005$ to 0.0018$)$ & 0.26 & 0 \\
\hline Early intervention response & Day 1 post-intervention albumin & 4 & 3844 & $0.0007(-0.0454$ to 0.0440$)$ & 0.97 & 0 \\
\hline Intervention response & Post-intervention albumin level & 5 & 3900 & $0.0173(-0.0268$ to 0.0613$)$ & 0.44 & 0 \\
\hline Intervention response & Post-intervention increase in albumin level & 5 & 3903 & $0.0116(-0.0120$ to 0.0352$)$ & 0.34 & 0 \\
\hline \multicolumn{7}{|c|}{ Human albumin compared to crystalloid fluid } \\
\hline Baseline mortality risk & Comparison group mortality & 7 & 3878 & $0.0000(-0.0055$ to 0.0054$)$ & 0.98 & 0 \\
\hline Baseline septic shock & Vasopressor use & 6 & 3854 & $0.0018(-0.0018$ to 0.0055$)$ & 0.33 & 0 \\
\hline Baseline septic shock & Lactate & 5 & 2636 & $0.0117(-0.0895$ to 0.0661$)$ & 0.77 & 0 \\
\hline Baseline hypoalbuminaemia & Baseline albumin level & 4 & 3832 & $-0.0129(-0.0427$ to 0.0189$)$ & 0.45 & 0 \\
\hline Daily intervention exposure & Daily albumin dose & 7 & 3878 & $0.0003(-0.0025$ to 0.0031$)$ & 0.82 & 0 \\
\hline Total intervention exposure & Total albumin dose & 7 & 3878 & $0.0006(-0.0009$ to 0.0022$)$ & 0.41 & 0 \\
\hline Early intervention response & Day 1 post-intervention albumin & 4 & 3832 & $0.0074(-0.0454$ to 0.0440$)$ & 0.97 & 0 \\
\hline Intervention response & Post-intervention albumin level & 4 & 3832 & $0.0182(-0.0259$ to 0.0624$)$ & 0.42 & 0 \\
\hline Intervention response & Post-intervention increase in albumin level & 4 & 3832 & $0.0124(-0.0114$ to 0.0362$)$ & 0.31 & 0 \\
\hline \multicolumn{7}{|c|}{ Human albumin compared to colloid fluid } \\
\hline Baseline mortality risk & Comparison group mortality & 11 & 299 & $0.0022(-0.0143$ to 0.0187$)$ & 0.79 & 0 \\
\hline Baseline septic shock & Vasopressor use & 8 & 229 & $0.0090(-0.0162$ to 0.0144$)$ & 0.91 & 0 \\
\hline Baseline septic shock & Lactate & 5 & 99 & $0.0025(-0.2359$ to 0.02409$)$ & 0.98 & 0 \\
\hline Baseline hypoalbuminaemia & Baseline albumin level & 2 & 80 & NA & NA & NA \\
\hline Daily intervention exposure & Daily albumin dose & 10 & 279 & $0.0015(-0.0032$ to 0.0061$)$ & 0.54 & 0 \\
\hline Total intervention exposure & Total albumin dose & 10 & 279 & $0.0004(-0.0001$ to 0.0023$)$ & 0.64 & 0 \\
\hline Early intervention response & Day 1 post-intervention albumin & 1 & 24 & NA & NA & NA \\
\hline Intervention response & Post-intervention albumin level & 2 & 80 & NA & NA & NA \\
\hline Intervention response & Post-intervention increase in albumin level & 2 & 80 & NA & NA & NA \\
\hline
\end{tabular}

$\mathrm{NA}=$ not applicable. 
Table 5| GRADE quality of evidence summary table for the comparisons of human albumin with control, crystalloid, or colloid fluid for adults with sepsis of any severity in critical or intensive care

\begin{tabular}{|c|c|c|c|c|c|c|c|c|c|c|c|c|}
\hline \multicolumn{7}{|c|}{ Quality assessment for comparison } & \multicolumn{2}{|c|}{ No of patients } & \multicolumn{2}{|c|}{ Effect } & \multirow[b]{2}{*}{ Quality } & \multirow[b]{2}{*}{ Importance } \\
\hline $\begin{array}{l}\text { No of } \\
\text { studies }\end{array}$ & Design & $\begin{array}{c}\text { Risk of } \\
\text { bias }\end{array}$ & Inconsistency & Indirectness & Imprecision & $\begin{array}{c}\text { Other } \\
\text { considerations }\end{array}$ & $\begin{array}{l}\text { Human } \\
\text { albumin }\end{array}$ & $\begin{array}{l}\text { Compared } \\
\text { fluid }\end{array}$ & $\begin{array}{c}\text { Relative } \\
\text { risk } \\
(95 \% \mathrm{Cl})\end{array}$ & Absolute & & \\
\hline \multicolumn{13}{|c|}{ Quality assessment for the comparison of human albumin with control fluid } \\
\hline \multicolumn{13}{|c|}{ All-cause mortality (follow-up ICU discharge to 90 days observation): } \\
\hline 16 & $\mathrm{RCT}$ & Serious $^{*}$ & $\begin{array}{l}\text { No serious } \\
\text { inconsistency }\end{array}$ & $\begin{array}{l}\text { No serious } \\
\text { indirectness }\end{array}$ & $\begin{array}{l}\text { No serious } \\
\text { imprecision }\end{array}$ & None & $\begin{array}{c}757 / 2068 \\
(36.6 \%)\end{array}$ & $\begin{array}{c}835 / 2122 \\
(39.3 \%)\end{array}$ & $\begin{array}{c}0.94 \\
(0.87 \text { to } \\
1.01)\end{array}$ & $\begin{array}{c}2 \text { fewer } \\
\text { per } 100 \\
\text { (from } 5 \\
\text { fewer to } 0 \\
\text { more) }\end{array}$ & $\begin{array}{c}+++ \\
\text { Moderate }\end{array}$ & Critical \\
\hline \multicolumn{13}{|c|}{ All-cause mortality in studies at low or unclear risk of bias (follow-up ICU discharge to 90 days observation): } \\
\hline 6 & $\mathrm{RCT}$ & $\begin{array}{l}\text { No } \\
\text { serious } \\
\text { risk }\end{array}$ & $\begin{array}{l}\text { No serious } \\
\text { inconsistency }\end{array}$ & $\begin{array}{c}\text { No serious } \\
\text { indirectness }\end{array}$ & $\begin{array}{l}\text { No serious } \\
\text { imprecision }\end{array}$ & None & $\begin{array}{c}699 / 1956 \\
(35.7 \%)\end{array}$ & $\begin{array}{c}767 / 1986 \\
(38.6 \%)\end{array}$ & $\begin{array}{c}0.93 \\
(0.86 \text { to } \\
1.01)\end{array}$ & $\begin{array}{c}3 \text { fewer } \\
\text { per } 100 \\
\text { (from } 5 \\
\text { fewer to } 0 \\
\text { more) }\end{array}$ & $\begin{array}{l}++++ \\
\text { High }\end{array}$ & Critical \\
\hline \multicolumn{13}{|c|}{ All-cause mortality in studies at high risk of bias (follow-up ICU discharge to 30 days observation): } \\
\hline 10 & $\mathrm{RCT}$ & Serious $†$ & $\begin{array}{l}\text { No serious } \\
\text { inconsistency }\end{array}$ & Serious $\ddagger$ & Serious§ & None & $\begin{array}{l}58 / 112 \\
(51.8 \%)\end{array}$ & $\begin{array}{l}68 / 136 \\
(50 \%)\end{array}$ & $\begin{array}{c}1.02 \\
(0.83 \text { to } \\
1.24)\end{array}$ & $\begin{array}{l}1 \text { more } \\
\text { per } 100 \\
\text { (from } 9 \\
\text { fewer to } \\
12 \text { more) }\end{array}$ & $\begin{array}{l}+ \text { Very } \\
\text { low }\end{array}$ & Critical \\
\hline
\end{tabular}

Quality assessment for the comparison of human albumin with crystalloid fluid

All-cause mortality (follow-up ICU discharge to 90 days observation):

\begin{tabular}{|c|c|c|c|c|c|c|c|c|c|c|c|c|}
\hline 7 & $\mathrm{RCT}$ & $\begin{array}{l}\text { No } \\
\text { serious } \\
\text { risk }\end{array}$ & $\begin{array}{l}\text { No serious } \\
\text { inconsistency }\end{array}$ & $\begin{array}{l}\text { No serious } \\
\text { indirectness }\end{array}$ & $\begin{array}{l}\text { No serious } \\
\text { imprecision }\end{array}$ & None & $\begin{array}{c}710 / 1937 \\
(36.7 \%)\end{array}$ & $\begin{array}{c}763 / 1941 \\
(39.3 \%)\end{array}$ & $\begin{array}{c}0.93 \\
(0.86 \text { to } \\
1.01) \\
\end{array}$ & $\begin{array}{c}3 \text { fewer } \\
\text { per } 100 \\
\text { (from } 6 \\
\text { fewer to } 0 \\
\text { more) }\end{array}$ & $\begin{array}{l}++++ \\
\text { High }\end{array}$ & Critical \\
\hline \multicolumn{13}{|c|}{ All-cause mortality in studies at low or unclear risk of bias (follow-up ICU discharge to 90 days observation): } \\
\hline 4 & $\mathrm{RCT}$ & $\begin{array}{l}\text { No } \\
\text { serious } \\
\text { risk }\end{array}$ & $\begin{array}{l}\text { No serious } \\
\text { inconsistency }\end{array}$ & $\begin{array}{l}\text { No serious } \\
\text { indirectness }\end{array}$ & $\begin{array}{l}\text { No serious } \\
\text { imprecision }\end{array}$ & None & $\begin{array}{c}690 / 1911 \\
(36.1 \%)\end{array}$ & $\begin{array}{c}746 / 1921 \\
(38.8 \%)\end{array}$ & $\begin{array}{c}0.93 \\
(0.86 \text { to } \\
1.01)\end{array}$ & $\begin{array}{c}3 \text { fewer } \\
\text { per } 100 \\
\text { (from } 5 \\
\text { fewer to } 0 \\
\text { more) }\end{array}$ & $\begin{array}{l}++++ \\
\text { High }\end{array}$ & Critical \\
\hline \multicolumn{13}{|c|}{ All-cause mortality in studies at high risk of bias (follow-up hospital discharge observation): } \\
\hline 3 & $\mathrm{RCT}$ & Serious & $\begin{array}{l}\text { No serious } \\
\text { inconsistency }\end{array}$ & $\begin{array}{c}\text { No serious } \\
\text { indirectness }\end{array}$ & Serious§ & None & $\begin{array}{c}20 / 26 \\
(76.9 \%)\end{array}$ & $\begin{array}{c}17 / 20 \\
(85.0 \%)\end{array}$ & $\begin{array}{c}0.92 \\
(0.71 \text { to } \\
1.20)\end{array}$ & $\begin{array}{l}7 \text { fewer } \\
\text { per } 100 \\
\text { (from } 25 \\
\text { fewer to } \\
17 \text { more) }\end{array}$ & ++ Low & Critical \\
\hline \multicolumn{13}{|c|}{ Quality assessment for the comparison of human albumin with colloid fluid } \\
\hline \multicolumn{13}{|c|}{ All-cause mortality (follow-up ICU discharge to 28 days observation): } \\
\hline 11 & $\mathrm{RCT}$ & 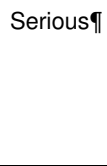 & $\begin{array}{l}\text { No serious } \\
\text { inconsistency }\end{array}$ & Serious $\ddagger$ & Serious§ & None & $\begin{array}{l}54 / 143 \\
(37.8 \%)\end{array}$ & $\begin{array}{l}58 / 156 \\
(37.2 \%)\end{array}$ & $\begin{array}{c}1.04 \\
(0.79 \text { to } \\
1.38)\end{array}$ & $\begin{array}{l}1 \text { more } \\
\text { per } 100 \\
\text { (from } 8 \\
\text { fewer to } \\
14 \text { more) }\end{array}$ & $\begin{array}{l}+ \text { Very } \\
\text { low }\end{array}$ & Critical \\
\hline \multicolumn{13}{|c|}{ All-cause mortality in studies at low or unclear risk of bias (follow-up ICU discharge to 28 days observation): } \\
\hline 3 & $\mathrm{RCT}$ & $\begin{array}{l}\text { No } \\
\text { serious } \\
\text { risk }\end{array}$ & $\begin{array}{l}\text { No serious } \\
\text { inconsistency }\end{array}$ & Serious $\ddagger$ & Serious§ & None & $\begin{array}{c}11 / 51 \\
(21.6 \%)\end{array}$ & $\begin{array}{c}21 / 65 \\
(32.3 \%)\end{array}$ & $\begin{array}{c}0.77 \\
(0.42 \text { to } \\
1.43)\end{array}$ & $\begin{array}{c}7 \text { fewer } \\
\text { per } 100 \\
\text { (from } 19 \\
\text { fewer to } \\
14 \text { more) }\end{array}$ & ++ Low & Critical \\
\hline \multicolumn{13}{|c|}{ All-cause mortality in studies at high risk of bias (follow-up ICU discharge to hospital discharge observation): } \\
\hline 8 & $\mathrm{RCT}$ & Serious $†$ & $\begin{array}{l}\text { No serious } \\
\text { inconsistency }\end{array}$ & Serious $\ddagger$ & Serious§ & None & $\begin{array}{c}43 / 92 \\
(46.7 \%)\end{array}$ & $\begin{array}{c}37 / 91 \\
(40.7 \%)\end{array}$ & $\begin{array}{c}1.13 \\
(0.83 \text { to } \\
1.53)\end{array}$ & $\begin{array}{l}5 \text { more } \\
\text { per } 100 \\
\text { (from } 7 \\
\text { fewer to } \\
22 \text { more) }\end{array}$ & $\begin{array}{l}+ \text { Very } \\
\text { low }\end{array}$ & Critical \\
\hline
\end{tabular}


Table 5 (continued)

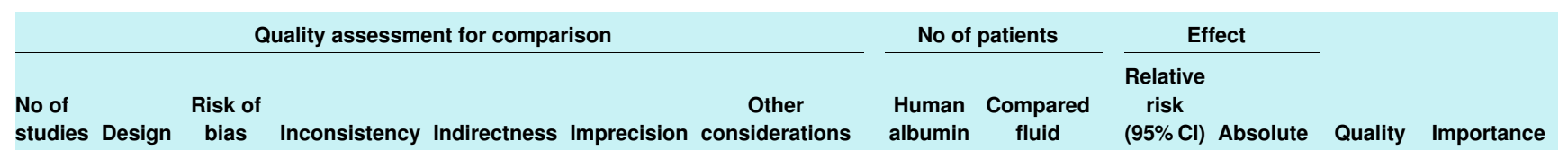

ICU=intensive or critical care unit. $\mathrm{RCT}=$ randomised clinical trial.

${ }^{*} 5.9 \%$ of patients were in studies judged as high risk of bias.

†All studies judged as high risk of bias.

¥Most patients were compared with high molecular weight hydroxyethyl starches that are now seldom available or used for adults with sepsis in critical or intensive care. This class of synthetic colloid has been associated with harm, and the European Medicines Agency on 6 March 2014 and the Food and Drug Administration on 25 November 2013 have concluded that hydroxyethyl starches solutions are no longer permitted for use in critically unwell adults with sepsis in parts of Europe and the US.24 25

§Wide 95\% confidence intervals, most included studies are small, and the information size is low.

I61.2\% patients were in studies judged as high risk of bias. 


\section{Figures}

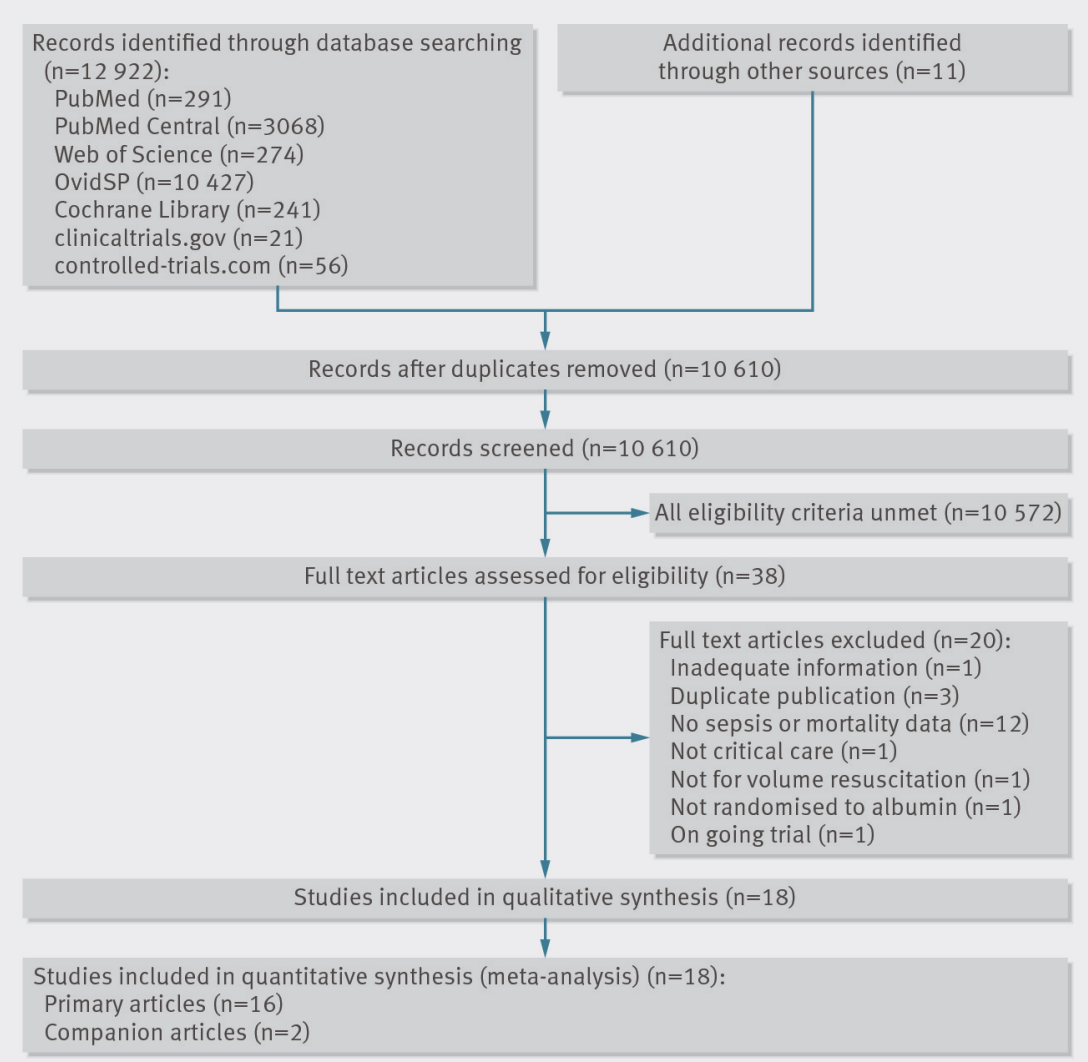

Fig 1 PRISMA (Preferred Reporting Items for Systematic reviews and Meta-Analyses) flow diagram detailing the search, identification, screening, and inclusion of randomised clinical trials assessed for inclusion. Reasons for exclusions were not mutually exclusive 
Study

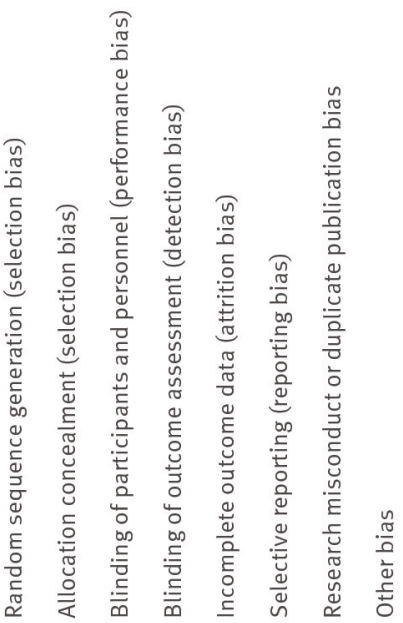

ALBIOS 2014

Boldt, Heesen et al 1996 Boldt, Müller et al 1996 Boldt, Müller et al 1996 Boldt et al 1995 Dolecek et al 2009 EARSS 2011

Friedman et al 2008

Haupt et al 1982

Metildi et al 1984

Palumbo et al 2006

Rackow et al 1983

Rackow et al 1989

SAFE 2004 and 2011

Veneman et al 2004

v Heijden 2009/Trof 2010

\begin{tabular}{|c|c|c|c|c|c|}
\hline & 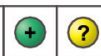 & (3) $\odot$ & & $\oplus$ & \\
\hline+ & (3) (3) & 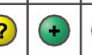 & 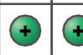 & 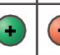 & 0 \\
\hline 3 & (3) (3) & (?) & $\odot \oplus$ & (4) & (3) \\
\hline (3) & (3) (3) & $\begin{array}{lll}8 & \oplus\end{array}$ & $\oplus \oplus$ & $(9)$ & 0 \\
\hline$\oplus$ & (3) (3) & (2) $\odot$ & $\odot 6$ & & $\Theta$ \\
\hline ๑) & (†) (3) & (2) & $\oplus$ & $\oplus$ & (3) \\
\hline$\oplus$ & $(\rightarrow$ (3) & (2) & $\odot 6$ & $\oplus$ & 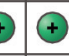 \\
\hline (3) & $(\rightarrow$ (3) & (2) $\odot$ & $\odot($ & (3) 6 & (5) \\
\hline (3) & (3) $\odot$ & $5 \odot$ & $\oplus 6$ & $\oplus$ & 5 (3) \\
\hline$\oplus$ & (3) $\odot$ & $\odot$ & $\odot 6$ & $\oplus 6$ & (3) \\
\hline$\oplus$ & (3) $\odot$ & $\odot \oplus$ & $\oplus$ & $\oplus$ & (3) \\
\hline (2) & (?) $\odot$ & $\oplus \odot$ & $\odot 6$ & $\oplus$ & (3) \\
\hline 3 & (3) $\odot$ & $\odot$ & $\oplus$ & $\oplus$ & (3) \\
\hline † & 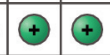 & $\oplus \odot$ & $\oplus$ & $(\oplus)$ & (3) \\
\hline (3) & (†) (?) & (2) $\odot$ & $\odot$ & $\Theta$ & \\
\hline & & & & & \\
\hline
\end{tabular}

Fig 2 Risk of bias summary displaying review authors' judgments about each risk of bias domain for each included study. Randomised clinical trials are listed alphabetically by author or study name 


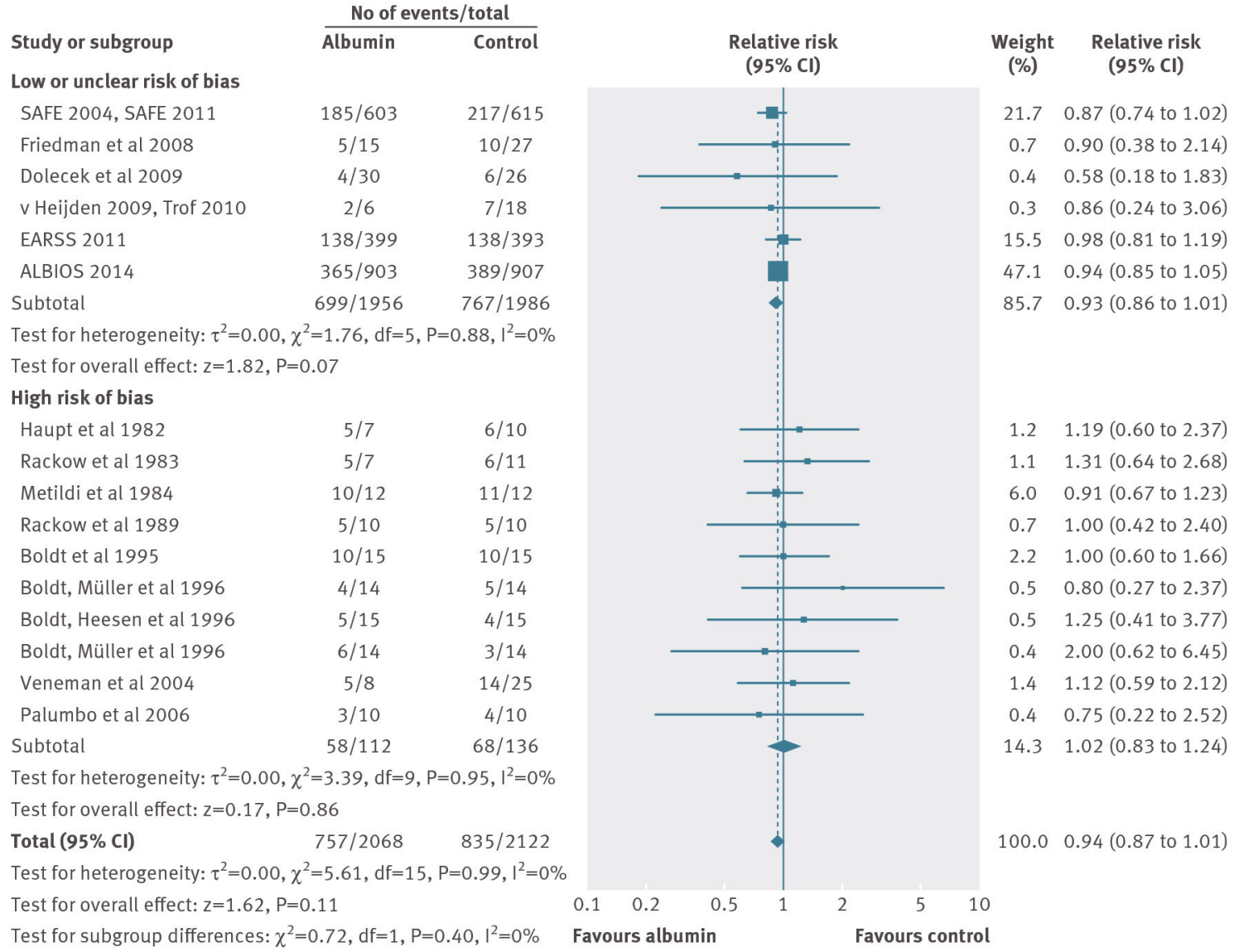

Fig 3 Relative risk of all-cause mortality in patients exposed to human albumin solutions compared with exposure to control fluids in the 16 randomised clinical trials included in analysis. Studies are ordered chronologically within subgroups 

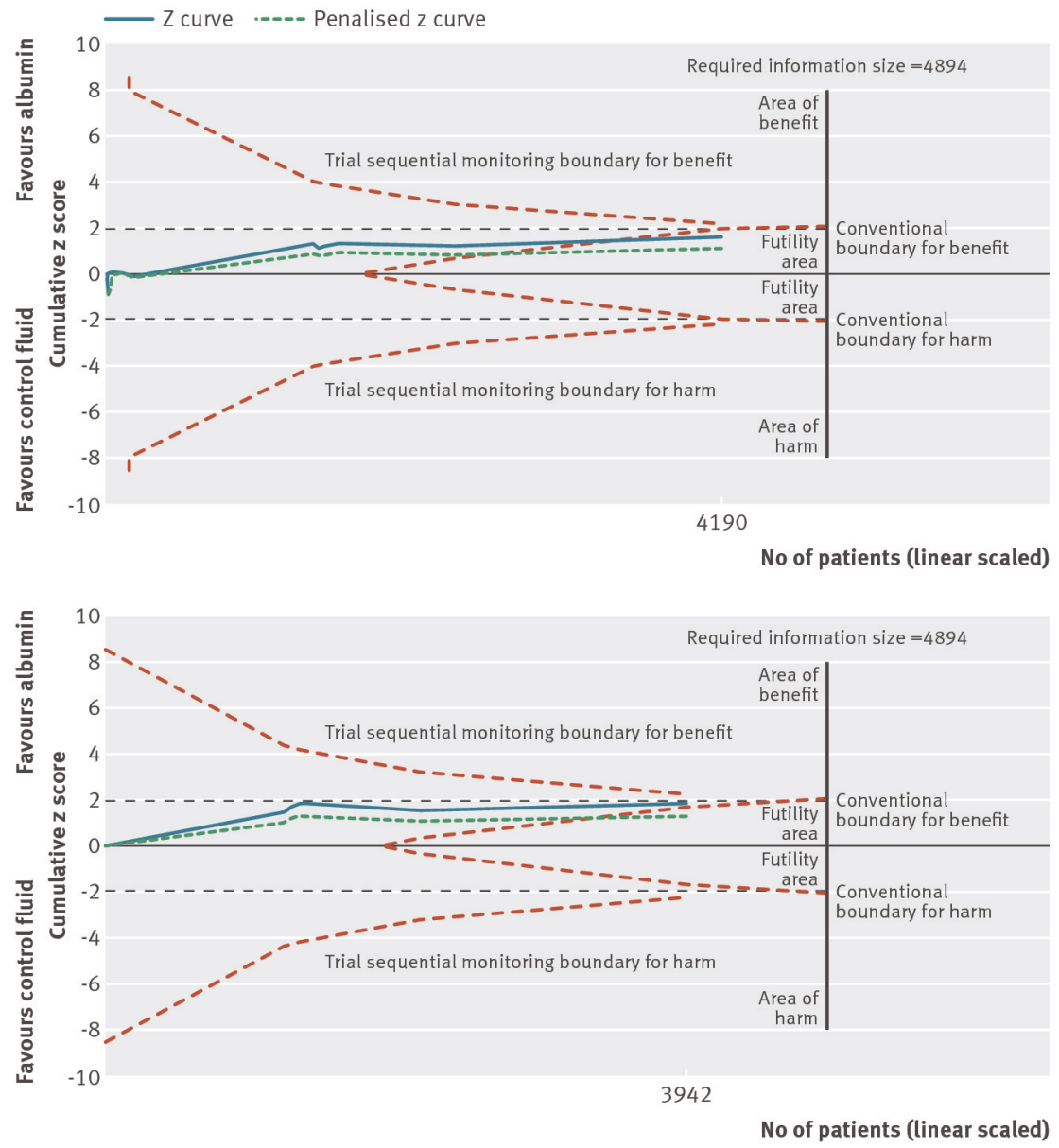

Fig 4 Trial sequential analysis of trials reporting mortality comparing pooled human albumin solutions with control fluids. Upper graph shows trial sequential analysis of the 16 primary trials; lower graph shows analysis of 6 primary trials after exclusion of studies at high risk of bias. A diversity adjusted information size of 4894 patients was calculated using a=0.05 (two sided), $\beta=0.20$ (power $80 \%$ ), $D^{2}=0 \%$, an anticipated relative risk of $10.0 \%$, and an event proportion of $38.6 \%$ in the control arm. The cumulative $z$ curve was constructed using a random effects model, and a penalised $z$ curve was also constructed. For all studies, the relative risk was 0.94 , and the $95 \%$ confidence interval was corrected to 0.87 to 1.02 , from 0.87 to 1.01. After exclusion of studies at high risk of bias, relative risk was 0.93 and the $95 \%$ confidence interval of 0.86 to 1.01 was corrected to 0.84 to 1.02 . 


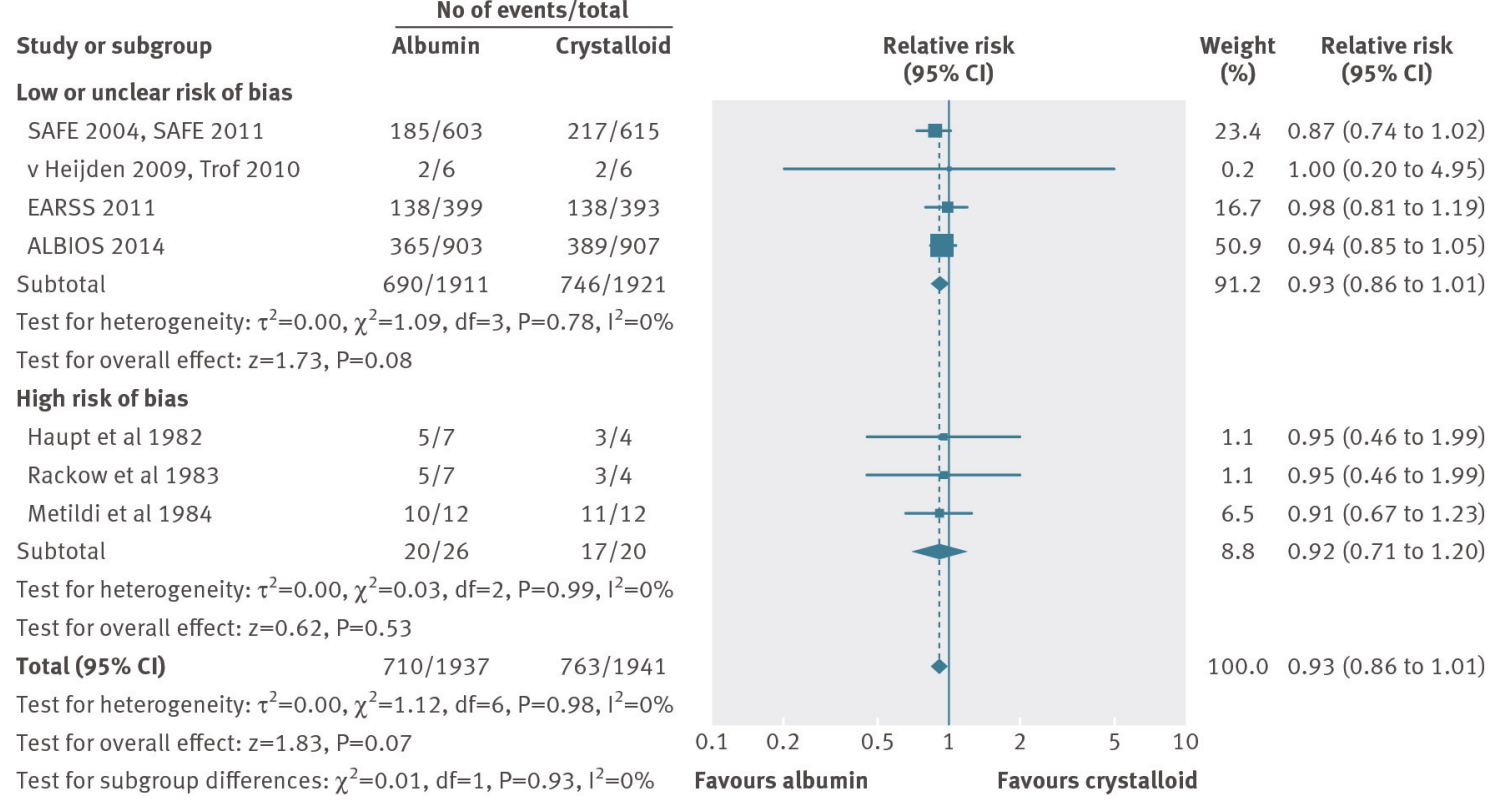

Fig 5 Relative risk of all-cause mortality in patients exposed to human albumin solutions compared with exposure to crystalloid fluids in seven clinical trials. Studies are ordered chronologically within subgroups 

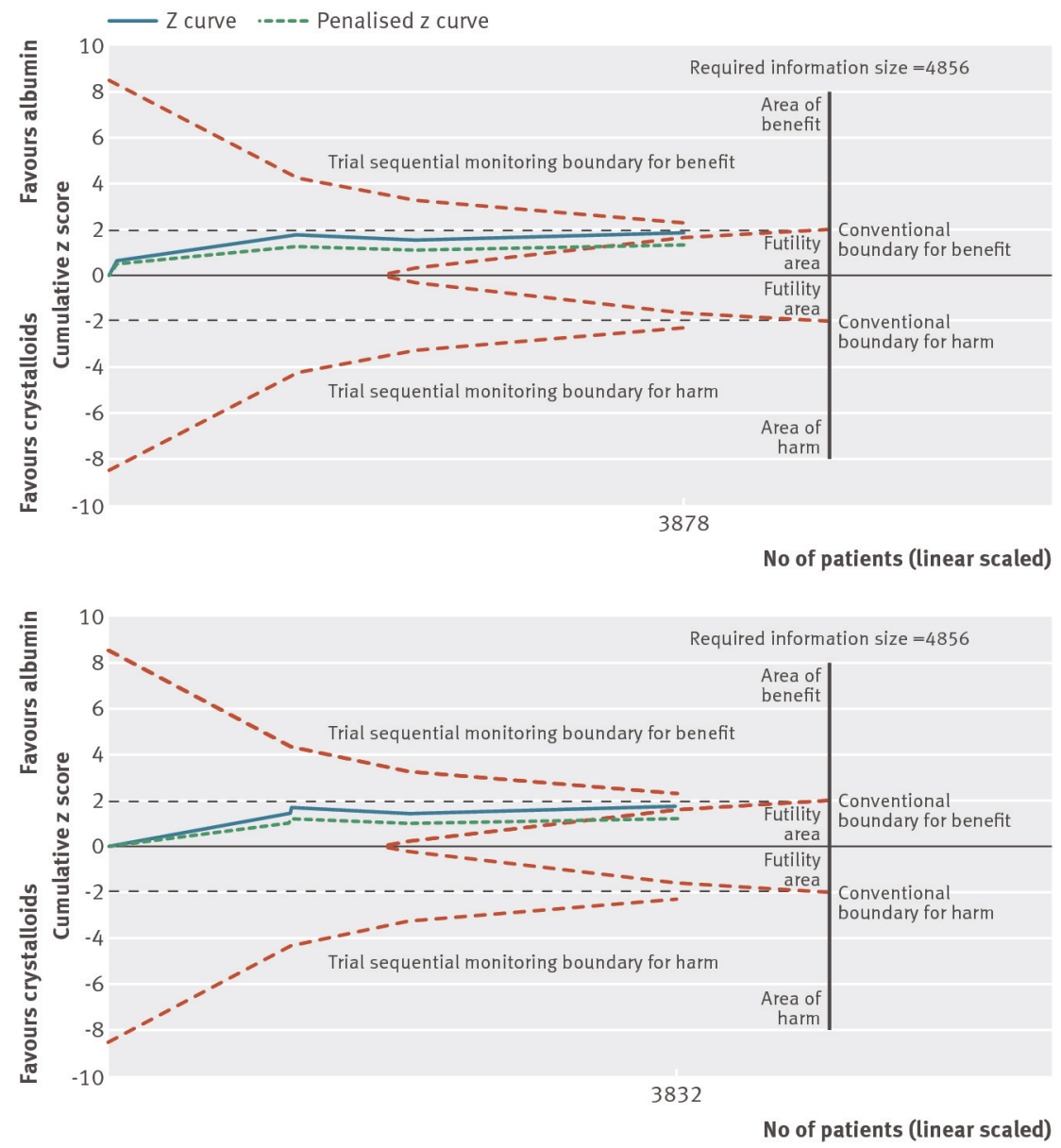

Fig 6 Trial sequential analysis of trials reporting mortality comparing pooled human albumin solutions with crystalloid fluids. Upper graph shows trial sequential analysis of the seven primary trials; lower graph shows analysis of four primary trials after exclusion of studies at high risk of bias. A diversity adjusted information size of 4856 patients was calculated using $a=0.05$ (two sided), $\beta=0.20$ (power $80 \%$ ), $D^{2}=0 \%$, an anticipated relative risk of $10.0 \%$, and an event proportion of $38.8 \%$ in the control arm. The cumulative $z$ curve was constructed using a random effects model, and a penalised $z$ curve was also constructed. For all studies, the relative risk was 0.93 , and the $95 \%$ confidence interval was corrected to 0.85 to 1.02 , from 0.86 to 1.01 . After exclusion of studies at high risk of bias, relative risk was 0.93 and the $95 \%$ confidence interval of 0.86 to 1.01 was corrected to 0.85 to 1.02 . 


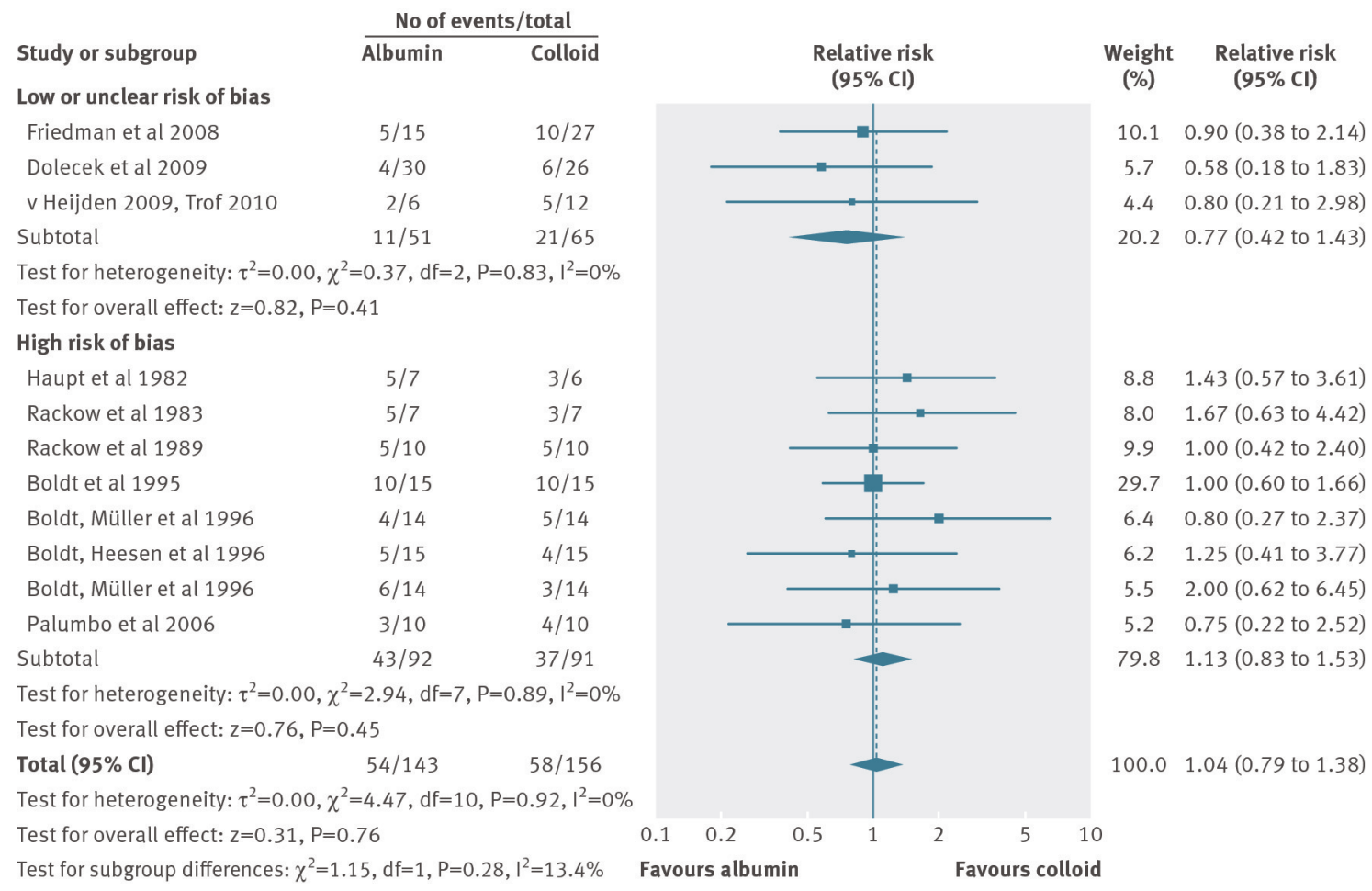

Fig 7 Relative risk of all-cause mortality in patients exposed to human albumin solutions compared with exposure to colloid fluids in 11 trials. Studies are ordered chronologically within subgroups 